\title{
Atmospheric Chemistry and the Biosphere: General Discussion
}

\section{Citation}

Archibald, Alexander, Stephen Arnold, Lustinian Bejan, Steven Brown, Martin Brüggemann, Lucy J. Carpenter, William Collins, Mathew Evans, Barbara Finlayson-Pitts, Christian George, Meredith Hastings, Dwayne Heard, C. N. Hewitt, Gabriel Isaacman-VanWertz, Markus Kalberer, Frank Keutsch, Astrid Kiendler-Scharr, Daniel Knopf, Jos Lelieveld, Eloise Marais, Andreas Petzold, A. Ravishankara, Jonathan Reid, Grazia Rovelli, Catherine Scott, Tomás Sherwen, Drew Shindell, Liselotte Tinel, Nadine Unger, Andreas Wahner, Timothy J. Wallington, Jonathan Williams, Paul Young, and Alla Zelenyuk. 2017. Atmospheric Chemistry and the Biosphere: General Discussion. Faraday Discussions 200: 195-228.

\section{Permanent link}

http://nrs.harvard.edu/urn-3:HUL.InstRepos:41275751

\section{Terms of Use}

This article was downloaded from Harvard University's DASH repository, WARNING: This file should NOT have been available for downloading from Harvard University's DASH repository.

\section{Share Your Story}

The Harvard community has made this article openly available. Please share how this access benefits you. Submit a story. 


\title{
Atmospheric chemistry and the biosphere: general discussion
}

\author{
Alexander Archibald, (iD) Stephen Arnold, Lustinian Bejan, Steven Brown, \\ Martin Brüggemann, (D) Lucy J. Carpenter, (D) William Collins, \\ Mathew Evans, (D) Barbara Finlayson-Pitts, Christian George, \\ Meredith Hastings, Dwayne Heard, (iD) C. N. Hewitt, (iD \\ Gabriel Isaacman-VanWertz, Markus Kalberer, Frank Keutsch, \\ Astrid Kiendler-Scharr, (iD) Daniel Knopf, (iD Jos Lelieveld, Eloise Marais, \\ Andreas Petzold, A. Ravishankara, Jonathan Reid, (D) Grazia Rovelli, \\ Catherine Scott, Tomás Sherwen, (D) Drew Shindell, Liselotte Tinel, \\ Nadine Unger, Andreas Wahner, Timothy J. Wallington, iD \\ Jonathan Williams, Paul Young (iD) and Alla Zelenyuk
}

\section{DOI: $10.1039 / C 7 F D 90038 D$}

Lucy Carpenter opened discussion of the paper by Christian George: Your previous work has emphasised the abiotic production of VOCs from surface ocean processes, mainly from photosensitized chemistry of surfactants. Does this work indicate that decay of microbial cells is the really dominant source of these VOCproducing surfactants and photosensitizers, and if so - does this really mean this is an abiotic process?

Christian George responded: As shown in our paper, VOC emissions increased drastically when the microbial cells were dying. Moreover, the highest VOC production was observed for the cellular fraction of the biofilms, i.e. intracellular material and cellular debris. Thus, we think that cell lysis is at least one of the major sources for such VOC-producing surfactants in the ambient environment. Besides this, anthropogenic pollutants could be an additional source for surfactants, however, such emissions would be of rather local importance. Although the source for the surfactants is biogenic in our study, the observed photochemical production of VOCs can be defined as entirely 'abiotic'.

Alexander Archibald said: Thank you for the paper which emphasises some new, unexpected results and possibly highlights poorly explored biogeochemical cycles. I was wondering how to link this in to the changes occurring in the Anthropocene? Do you think that changes in temperature $/ \mathrm{CO}_{2}$ will affect this? How about changes in nitrogen deposition/oxidants? 
Christian George responded: Although our results describe photochemical processes in the ambient environment that are not limited to the Anthropocene, such reactions at the air/water interface are certainly altered by anthropogenic emissions. For example, it was shown that nutrients from agriculture stimulate growth of microorganisms and algae in coastal waters. ${ }^{1}$ Eventually such artificially enhanced blooms will lead to the emission of surfactants, which might then enhance VOC production from interfacial photochemistry. Nonetheless, further studies will be needed to assess the extent of anthropogenic influences on these mechanisms.

1 K. Davidson et al., J. Environ. Manage., 2014, 146, 206-216.

A. Ravishankara remarked: You suggested that the photochemical reactions you discussed occur at the surface of the liquid. Two questions: first, can you please elaborate on how you concluded that your studies isolated reactions only at the surface? Second, could not photochemical process take place in the top layer (a few meters) of oceans and lakes, and thus influence atmospheric composition?

Christian George replied: For the first question, we cannot entirely exclude any photochemistry occurring in the bulk. However, our previous work supports our conclusion, that surfactant-enriched air/water interfaces are preferred venues for the photochemical production of VOCs. Moreover, VOC emission always started immediately with irradiation of the sample, indicating that no diffusion processes in the bulk were slowing down the observed emissions. For the second question, indeed a variety of other photochemical processes can take place in surface seawater. A recent review by Carpenter et al. ${ }^{1}$ summarizes the most important production pathways for smaller VOCs in marine environments. However, these mechanisms do not yield unsaturated and functionalized VOCs, as observed in our study.

\section{L. J. Carpenter and P. D. Nightingale, Chem. Rev., 2015, 115, 4015-4034.}

Jonathan Williams noted: There is a strong increase in the emissions when you kill the living organisms in your samples. You interpret this as the result of cell wall splitting and the associated release of intracellular organic species. Could an alternative explanation be that under normal conditions the living bacteria are rapidly consuming the emissions (created via the mechanism you propose) and that when this consumption stops when they are killed the emission rate shoots up to the total emission?

Christian George answered: As described in the paper, we think that VOC production occurs primarily due to photochemistry at the air/water interface. Thus, a consumption of the produced VOCs by living organisms seems rather unlikely, since this would predominantly take place in the bulk.

Jonathan Williams asked: Following on from the previous question, do you know if the products you see are effectively taken up by living microbes as well?

Christian George responded: As stated in my previous answer, we do not see any evidence for such a VOC consumption by microorganisms. 
Steven Brown addressed Martin Brüggemann: Can you talk about your poster in terms of benchmarking on a global basis? Considering DMS as a benchmark, what fraction of DMS could you account for with a mechanism like this?

Martin Brüggemann communicated in response: Current estimates on annual DMS emissions from the oceans into the atmosphere are in the range of 28.1 (17.6-34.4) $\mathrm{Tg}$ of sulfur, i.e. 54.5 (34.1-66.7) $\mathrm{Tg}$ of DMS. ${ }^{1}$ In comparison, our calculations indicate an annual VOC emission flux of up to $74 \mathrm{Tg}$ per year from interfacial photochemistry. However, in contrast to DMS emissions, this VOC flux is composed of dozens of compounds (see our paper for a complete list). Therefore, single VOCs make up only a rather small fraction of annual DMS emissions. For example, global isoprene emissions are estimated to be in the range of 0.5-0.9 Tg per year. Nonetheless, since this photochemical VOC production is not immediately coupled to biology, especially in remote oligotrophic regions, this may be a major source for VOCs.

1 A. Lana et al., Global Biogeochem. Cycles, 2011, DOI: 10.1029/2010GB003850.

Meredith Hastings asked: What do you suggest is a way to distinguish biogenic versus non-biogenic emissions of the type you are suggesting are important? Does this require continuous observations? At what time scale?

Christian George answered: Currently there is no established approach to distinguish between VOC emissions from biology and from photochemistry at the air/water interface. Moreover, field observations are typically scarce and only available for short time periods, impeding a clear source apportionment. Nonetheless, recently a promising study was published by Mungall et al., ${ }^{1}$ reporting on direct observations of OVOC production from interfacial photochemistry.

1 E. L. Mungall et al., Proc. Natl. Acad. Sci. U. S. A., 2017, 114, 6203-6208.

Astrid Kiendler-Scharr remarked: The reference data for pure water shown in Fig. 2 of your paper (blue line) seem to be lacking the level of noise detected for the other three experiments, even for the part of the experiment before the lights are on. Can you explain why this would be the case?

Christian George replied: The reason for the apparent low level of noise is solely due to the scaling of the axes.

Astrid Kiendler-Scharr queried: On a very speculative level, I would like to ask whether the mechanism introduced by you and the mechanisms leading to isoprene exhalation by humans have something in common.

Christian George replied: Up to now, we don't see any link between these mechanisms.

Jonathan Reid said: The measurements of surface tension that you present suggest that the surface enrichment of organic components is quite low with a surface tension that is only marginally below water. As a comparison, such 
a surface tension can be observed in aqueous dicarboxylic acids solutions, water soluble organic compounds identified by you in the extract, at concentrations of $\sim 0.1 \mathrm{M}$. To what extent do you think there is competition between photochemistry at the surface and in the bulk? Is all of the chemistry you describe happening exclusively at the surface?

Christian George answered: It should be noted that not all of the compounds enriched at the air/water interface are necessarily strong surfactants which efficiently decrease surface tension. We note that in addition to straight chain surfactant molecules, exopolymeric substances, hydrated gel materials, organic particulates and fragments of marine microbes also concentrate there. ${ }^{1-3}$ Furthermore, it was shown that already very low concentrations of a surfactant at the air/water interface can give VOC emissions in the ppb range upon irradiation. ${ }^{4}$ As stated in one of my previous answers, we cannot entirely exclude influences from photochemistry in the bulk, however, to the best of our knowledge there are no alternative mechanisms explaining the observed formation of unsaturated OVOCs upon irradiation.

1 Wurl and Holmes, Mar. Chem., 2008, 110, 89-97.

2 Aller et al., J. Aerosol Sci., 2005, 36, 801-812.

3 Zhang et al., J. Colloid Interface Sci., 2003, 264, 128-159.

4 R. Ciuraru et al., Environ. Sci. Technol., 2015, 49, 13199-13205

Iustinian Bejan asked: Did you measure any light dependency? Switching to a different number of lamps could see if the emissions are linear with the light and may improve the knowledge about this process. Additionally, a good test would be to replace the air used to drive out the emissions with nitrogen. If there are pure light dependent processes the bath gas should not affect the emissions. If there is oxygen dependency - could it be a revived cell issue?

Christian George answered: Up to now, we did not conduct any experiments of this kind for biofilm samples. However, Rossignol et al. ${ }^{1}$ and Tinel et al. ${ }^{2}$ showed in similar experiments that molecular oxygen addition occurs at a surfactantcoated air/water interface due to photosensitized reactions, eventually yielding unsaturated and functionalized VOCs. Thus, a light dependency can be assumed for these interfacial processes.

1 Rossignol et al., Science, 2016, 699-702.

2 Tinel et al., Environ. Sci. Technol., 2017.

Iustinian Bejan then asked: Did you change the surface of the biofilm system? It would be interesting to check the emission dependency on surface for the same layer thickness (with an actually constant quantity of dead cells) and the layer thickness dependency (dependency per gram) while keeping the surface constant.

Christian George replied: We did not conduct any experiments of this kind yet. However, they might indeed help to gain additional knowledge on the underlying mechanisms.

Alexander Archibald opened a general discussion of the paper by Tomás Sherwen: Really nice talk Tomás. My question is about the large ozone loss in the 
Mediterranean. Losing $30 \mathrm{ppb}$ sounds like a huge amount to me. There is some evidence that models overestimate ozone in this region ${ }^{1}$ and I wondered if you felt that the modelled halogen ozone loss would bring your model results closer to the observations available in this region or further away? And if the latter, would this be a bad thing?

1 P. Zanis et al., Atmos. Chem. Phys., 2014, 14, 115-132.

Tomás Sherwen replied: We present comparisons against ozone observations from the UK air-quality network and for these sites we do not see a systematic overestimate in our model. Due to the availability of observations at the time of writing the manuscript, a comparison with European (AirBase/EMEP) observations was not presented. Our more recent work comparing the model to the AirBase/EMEP observations suggests that the modelled ozone is improved in the Mediterranean region with addition of halogens. We will publish this in the future.

Steven Brown addressed Tomás Sherwen and Mathew Evans: $\mathrm{O}_{3}$ is often correct in air quality models. Your model required halogens to reproduce $\mathrm{O}_{3}$, but other models do not. Are all previous models wrong that didn't include halogen chemistry? Or are other models likely correct for the wrong reasons?

The difference between $\mathrm{Br}, \mathrm{I}$, and $\mathrm{Cl}$ is that chlorine gives a positive change in $\mathrm{O}_{3}$, but $\mathrm{Br}$ and I produce large negative changes. But Br and I come mainly from natural sources, while $\mathrm{Cl}$ is from $\mathrm{ClNO}_{2}$ and is anthropogenic. Should these all be considered together?

Mathew Evans replied: All halogens have both anthropogenic and natural sources. Much of the iodine in the atmosphere comes from the ocean inorganic source which is driven by surface ozone, much of which is anthropogenic in origin. There are routes to get sea-salt chlorine into the gas phase which don't involve $\mathrm{N}_{2} \mathrm{O}_{5}$. In our model (almost undoubtedly not right but where else are we to start?) most of the chlorine (87\%) comes from non-ClNO $\mathrm{O}_{2}$ sources. In the polluted boundary-layer, $\mathrm{ClNO}_{2}$ dominates but for most of the atmosphere it does not. So we need to be careful when we allocate halogens into being either natural or anthropogenic. Their chemical cycles are also closely coupled which makes separating them clearly difficult. In our recent paper $^{1}$ we have tried to look at the difference in halogens between the "pre-industrial" and the present day. Almost universally the concentrations of halogen have increased since the pre-industrial era. We are only just starting to understand the role of halogens in the tropospheric chemistry system. We need new observations (notably $\mathrm{HOI}, \mathrm{HBr}, \mathrm{HOBr}$, $\mathrm{ClNO}_{2}, \mathrm{HCl}, \mathrm{HOCl}$ ) together with our current techniques to make wide-spread observations in a range of chemical environments to be able to test our models.

1 T. Sherwen et al., Atmos. Chem. Phys., 2017, 17, 1557-1569.

Tomás Sherwen added: There are many reasons for a difference in ozone between models. This can be differences in sinks and sources. There is evidence for ozone loss through halogens ${ }^{1}$ so this chemical process should be considered by our models. If ozone is currently captured by models that don't consider 
halogen chemistry, this could be explained by an overestimate in sinks or an underestimate in sources.

Reactive chlorine has both natural and anthropogenic sources. Our model predicts that $\mathrm{Cl}_{y}$ production from $\mathrm{N}_{2} \mathrm{O}_{5}$ is a significant source at the surface, but a smaller player globally in our model $(15 \%){ }^{2}$ The net result of this chemistry is not necessarily an increase in $\mathrm{O}_{3}$ as this will depend critically on the $\mathrm{NO}_{x}$ concentration. We find that the net effect on ozone over the whole region (whether global or regional) is a decrease due to chlorine chemistry. This is due to a decrease in the $\mathrm{NO}_{x}$ concentrations through halogen nitrate hydrolysis. The effect of halogens on the $\mathrm{NO}_{x}$ budget is discussed in further detail in Schmidt et $a .^{3}$ As we say in the paper: "It seems likely therefore that when all chlorine sources are considered together they lead to a reduction in $\mathrm{O}_{3}$ mixing ratios...".

1 K. A. Read et al., Nature, 2008, 453, 1232-1235.

2 T. Sherwen, J. A. Schmidt, M. J. Evans, L. J. Carpenter, K. Großmann, S. D. Eastham, D. J. Jacob, B. Dix, T. K. Koenig, R. Sinreich, I. Ortega, R. Volkamer, A. Saiz-Lopez, C. PradosRoman, A. S. Mahajan and C. Ordóñez, Atmos. Chem. Phys., 2016, 16, 12239-12271.

3 J. A. Schmidt, D. J. Jacob, H. M. Horowitz, L. Hu, T. Sherwen, M. J. Evans, Q. Liang, R. M. Suleiman, D. E. Oram, M. L. Breton, C. J. Percival, S. Wang, B. Dix and R. Volkamer, J. Geophys. Res.: Atmos., 2016, 121, 11819-11835

Mathew Evans remarked: Just because a model simulates roughly the correct ozone, it doesn't mean it is 'correct'. Two wrongs have been known to make a right in the modelling world. Historically models which just transported stratospheric ozone into the troposphere and deposited ozone to the surface seemed to simulate the tropospheric ozone concentration 'correctly'. There are many other areas of our understanding of tropospheric ozone which would lead to compensating increases - ocean deposition, VOC oxidation etc. These models are 'subconsciously' tuned to observations all the time. I'm sure that there will be a way of increasing model ozone concentration if it was found that the inclusion of halogens led to a significant underestimate.

Jos Lelieveld noted: Bromine and iodine chemistry are important; you see an influence on the diel ozone cycle over the Mediterranean. Does it change in terms of including iodine and bromine chemistry?

Tomás Sherwen responded: We've not looked at changes in the diel ozone cycle in the Mediterranean, but hope to do so in the future. We have previously presented the changes in diel ozone cycling due to halogens at Cape Verde in the remote tropical marine boundary layer using a global model in Sherwen et al., ${ }^{1}$ which follows on from previous box-modelling work into this by Read et al. ${ }^{2}$

1 T. Sherwen, M. J. Evans, L. J. Carpenter, S. J. Andrews, R. T. Lidster, B. Dix, T. K. Koenig, R. Sinreich, I. Ortega, R. Volkamer, A. Saiz-Lopez, C. Prados-Roman, A. S. Mahajan and C. Ordóñez, Atmos. Chem. Phys., 2016, 16, 1161-1186.

2 K. A. Read et al., Nature, 2008, 453, 1232-1235.

Jonathan Williams said: Given that nitryl chloride is a key compound in the halogen and ozone chemistry you are investigating, does it make sense to determine halogen impacts on ozone when the modelled and measured $\mathrm{ClNO}_{2}$ do not match? 
Tomás Sherwen replied: The only source of $\mathrm{ClNO}_{2}$ in the model is from $\mathrm{N}_{2} \mathrm{O}_{5}$ uptake onto sea-salt aerosol. This appears to underestimate the sources in continental regions. Whether this is due to acid displacement of $\mathrm{HCl}$ from sea-salt, followed by uptake into sulphate aerosol, or from direct continental sources of $\mathrm{HCl}$ which then become chloride, is currently scientifically unclear. The paper acknowledges that the model appears to underestimate $\mathrm{ClNO}_{2}$, especially in continental regions, and this likely leads to us underestimating the impact of $\mathrm{ClNO}_{2}$ chemistry on European ozone. This is not the only failure of the model when it comes to chlorine chemistry. Globally we calculate $\sim 62 \%$ of the global $\mathrm{Cl}_{y}$ source being from organo-halogens. ${ }^{1}$ Given that the model used here does not include a range of short lived chlorine containing organic species, ${ }^{2}$ it likely underestimates the total $\mathrm{Cl}$ source significantly. We are working on improving this chemistry in subsequent versions of the model. The wider impact of the other halogens (BrO, IO) are also significant in the model both due to local chemistry and global impacts with significant uncertainties from gas phase kinetics, emissions rates, heterogenous processing etc. Philosophically though, the question seems to suggest that model development and evaluation should only occur when the models are capable of perfectly simulating observations or when a complete process level understanding is available. This appears to create a chicken and egg situation. The models cannot be evaluated until they are perfect, but the models need to be evaluated if they are to improve. Imperfect models need to be used to help guide future field and laboratory studies and future model development. We believe we have been honest about the performance of our model against observations and identifying its failings. We do not believe that suppressing modelling until they are able to "match" observations is going to help drive our understanding of atmospheric processes forwards in a useful way. Modelling and measurement need to go hand in hand, informing one-another and supporting the different scientific methodologies. However, much of the impact that we see in the model comes from the global response of ozone to halogens and the regional impact. This is much more driven by iodine and bromine chemistry.

1 T. Sherwen, J. A. Schmidt, M. J. Evans, L. J. Carpenter, K. Großmann, S. D. Eastham, D. J. Jacob, B. Dix, T. K. Koenig, R. Sinreich, I. Ortega, R. Volkamer, A. Saiz-Lopez, C. PradosRoman, A. S. Mahajan and C. Ordóñez, Atmos. Chem. Phys., 2016, 16, 12239-12271.

2 R. Hossaini, M. P. Chipperfield, A. Saiz-Lopez, R. Fernandez, S. Monks, P. Brauer and R. von Glasow, J. Geophys. Res.: Atmos., 2016, 121, 14271-14297.

Dwayne Heard commented: In the paper several datasets of radical species from field campaigns are mentioned, in the context of comparison with the output from the GEOS-CHEM model. It is recognised that the paper is only looking to give a rough comparison with measurements, but it is worth pointing out that the footprint of the measurement technique can make quite a difference. For example, for IO radicals, datasets at Mace Head and Brittany are discussed with a range of values of the mixing ratio of IO given. It should be stressed that the range of values quoted comprises both long-path DOAS measurements of IO and in situ measurements of IO using laser-induced fluorescence. It is known that for the same site these values can differ significantly owing to the heterogeneity of the distribution of iodine sources. For example, at Mace Head, DOAS and LIF values vary by up to a factor of 10 , as the LIF instrument is very close to the exposed macroalgae (so gives higher mixing ratios) whereas the long path of the DOAS over several $\mathrm{km}$ is mostly over the ocean surface rather than exposed macroalgae so the 
average mixing ratio along the long-path is much less, with the ratio depending on the depth of the tide and the wind direction.

Tomás Sherwen replied: As you point out there are a range of issues when comparing the concentration of short lived species both with other observations and with models. The current observational datasets for species such as IO have focussed on coastal locations with substantial spatial gradients which leads to these differences between local and spatially integrated techniques. Future observations in open ocean locations where these gradients are less defined would probably offer a more critical and useful assessment of model performance.

Dwayne Heard asked: The paper reports an average reduction in surface $\mathrm{OH}$ mixing ratio of $16 \%$. I wondered what the equivalent change was for $\mathrm{HO}_{2}$ radicals? One could imagine this would be larger, owing to the direct reaction of $\mathrm{HO}_{2}$ with IO and BrO. Can the change in $\mathrm{OH}$ and $\mathrm{HO}_{2}$ when halogens are included be compared with existing field datasets of $\mathrm{OH}$ and $\mathrm{HO}_{2}$ ? There are some in the Mediterranean, for example during the MINOS campaign in Crete. In favourable cases, it may be possible to see if there is a better agreement between model and measurements if halogens are included, which would provide further evidence for the impact of halogens. The situation is somewhat different for box model comparisons when halogens are included, as $\mathrm{O}_{3}$ is then usually fixed by measurements, whereas if $\mathrm{O}_{3}$ is not constrained then $\mathrm{O}_{3}$ would be expected to decrease and hence impact $\mathrm{HO}_{x}$.

Tomás Sherwen answered: We have not compared against $\mathrm{OH}$ and $\mathrm{HO}_{2}$ observations here. We have reported global changes in $\mathrm{HO}_{x}$ in more detail elsewhere. ${ }^{1,2}$ The change in $\mathrm{HO}_{2}$ is more complex. The average predicted surface $\mathrm{HO}_{2}$ in the simulations presented here decreases by $6.5 \%$ on inclusion of halogens ("HAL" vs. "NOHAL"). However, this is highly variable. Over continental regions, $\mathrm{HO}_{2}$ concentrations can increase by as much as $48 \%$, whereas over the oceans they can decrease by as much as $41 \%$.

I agree that box models will give a misleading interpretation of halogen-driven changes in $\mathrm{HO}_{x}$ due to fixing $\mathrm{O}_{3}$. We have previously discussed the global change in $\mathrm{OH}$ for the different halogens and the relative changes in (i) primary $\mathrm{OH}$ production, due to decreased $\mathrm{O}_{3}$, and (ii) a new source of $\mathrm{OH}$ from conversion of $\mathrm{HO}_{2}$ to $\mathrm{OH}$ by $\mathrm{XO}(\mathrm{X}=\mathrm{Cl}, \mathrm{Br}, \mathrm{I})$ photolysis. ${ }^{1,2}$

1 T. Sherwen, M. J. Evans, L. J. Carpenter, S. J. Andrews, R. T. Lidster, B. Dix, T. K. Koenig, R. Sinreich, I. Ortega, R. Volkamer, A. Saiz-Lopez, C. Prados-Roman, A. S. Mahajan and C. Ordóñez, Atmos. Chem. Phys., 2016, 16, 1161-1186.

2 T. Sherwen, J. A. Schmidt, M. J. Evans, L. J. Carpenter, K. Großmann, S. D. Eastham, D. J. Jacob, B. Dix, T. K. Koenig, R. Sinreich, I. Ortega, R. Volkamer, A. Saiz-Lopez, C. PradosRoman, A. S. Mahajan and C. Ordóñez, Atmos. Chem. Phys., 2016, 16, 12239-12271.

Stephen Arnold queried: Do you have an idea of how much this halogen effect may have changed from pre-industrial to present day?

Tomás Sherwen responded: Our model predicts the activity of halogens in the troposphere has increased from the preindustrial to present day, and we have discussed this with a global context elsewhere. ${ }^{1}$ This increase is due to increased 
sources, including anthropogenic release of organo-halogen species, increased $\mathrm{ClNO}_{2}$ concentrations due to increased $\mathrm{NO}_{x}$ mixing ratios, and an increased abiotic ocean surface iodine source. The abiotic inorganic iodine source (HOI, $\mathrm{I}_{2}$ ) increases due to a parameterised dependence on ozone mixing ratios ${ }^{2}$ which have increased from preindustrial to present. We also predict surface concentrations of $\mathrm{ClNO}_{2}$ to dramatically increase over regions where increases in $\mathrm{NO}_{x}$ concentration are highest, such as Europe (see Fig 4 . in Sherwen et al. ${ }^{1}$ ), leading to an increase in the importance of this chemistry in present polluted regions with a coastal influence.

1 T. Sherwen, M. J. Evans, L. J. Carpenter, J. A. Schmidt and L. J. Mickely, Atmos. Chem. Phys., 2017, 17, 1557-1569.

2 L. J. Carpenter, S. M. MacDonald, M. D. Shaw, R. Kumar, R.W. Saunders, R. Parthipan, J. Wilson and J. M. C. Plane, Nature Geosci., 2013, 6, 108-111.

William Collins asked: Is your halogen chemistry the same as used in Parrella et al.? If adding halogens reduces the modelled ozone below observations, does that mean we must be underestimating anthropogenic ozone production efficiency elsewhere in the models? Therefore would this increase the ozone RF when using your modelled ozone burden for the pre-industrial and observed ozone burden for the present?

Tomás Sherwen responded: The halogen simulation used here builds on that described by Parrella et al. ${ }^{1}$ and other developments to the halogen simulation ${ }^{2-4}$ as described by Sherwen et al. ${ }^{5}$ It thus now includes a representation of the $\mathrm{I}, \mathrm{Br}$ and $\mathrm{Cl}$ chemistry, whereas Parrella just included $\mathrm{Br}$. We are currently assessing how the inclusion of halogens changes the model's ability to simulate present day and past $\mathrm{O}_{3}$. We show a limited comparison against UK AQ monitoring sites in this paper (Fig. 3, 4, and SI3), a limited but global comparison for the present day in Sherwen et al. ${ }^{5}$ and comparisons with pre-industrial values in Sherwen et al. ${ }^{6}$ Globally the model improves in some locations and regresses in others. The overall performance is not completely clear but we feel that the inclusion of halogens probably removes the model's high bias and replaces it with a low bias. This would suggest a need for either an additional source of $\mathrm{O}_{3}$ (changes in $\mathrm{NO}_{x}$ or VOC chemistry?) or a reduction in the $\mathrm{O}_{3}$ sink (ozone dry deposition?). ${ }^{8}$ The impact of these changes on ozone radiative forcing is unclear. We think that halogens in themselves tend to reduce $\mathrm{O}_{3}{ }^{6}$ However, if observations suggest that an additional source of $\mathrm{O}_{3}$ is needed, this would tend to increase the $\mathrm{O}_{3}$ radiative forcing. Overall we believe that our understanding of the chemistry acting to determine the $\mathrm{O}_{3}$ concentration in the troposphere is more uncertain than that reflected in the current spread of models used to determine $\mathrm{O}_{3}$ radiative forcings by the IPCC. We also note that the spread in those models probably underestimates the uncertainty in the chemistry that they do include. ${ }^{7}$ There is still work to be done to understand the chemistry needed to represent the change in $\mathrm{O}_{3}$ between the pre-industrial and the present day. Thus we believe that there is significant uncertainty in what is the important chemistry occurring in the troposphere which is not reflected in the IPCC $\mathrm{O}_{3}$ radiative forcing calculations. We also note that there is significant uncertainty in the rate kinetics used. If this chemistry was considered in a model that did not contain the same level of ozone production (natural or anthropogenic) as in our model then an underestimation in ozone mixing ratios would be expected. Obviously an overestimation in the 
ozone sink from deposition, as suggested by Luhar et al., ${ }^{8}$ could also explain capturing ozone observations when a loss route through halogens is not considered.

1 J. P. Parrella, D. J. Jacob, Q. Liang, Y. Zhang, L. J. Mickley, B. Miller, M. J. Evans, X. Yang, J.

A. Pyle, N. Theys and M. Van Roozendael, Atmos. Chem. Phys., 2012, 12, 6723-6740.

2 S. D. Eastham, D. K. Weisenstein and S. R. H. Barrett, Atmos. Environ., 2014, 89, 52-63.

3 J. A. Schmidt, D. J. Jacob, H. M. Horowitz, L. Hu, T. Sherwen, M. J. Evans, Q. Liang, R. M. Suleiman, D. E. Oram, M. L. Breton, C. J. Percival, S. Wang, B. Dix and R. Volkamer, J. Geophys. Res.: Atmos., 2016, 121, 11819-11835.

4 T. Sherwen, M. J. Evans, L. J. Carpenter, S. J. Andrews, R. T. Lidster, B. Dix, T. K. Koenig, R. Sinreich, I. Ortega, R. Volkamer, A. Saiz-Lopez, C. Prados-Roman, A. S. Mahajan and C. Ordóñez, Atmos. Chem. Phys., 2016, 16 1161-1186.

5 T. Sherwen, J. A. Schmidt, M. J. Evans, L. J. Carpenter, K. Großmann, S. D. Eastham, D. J. Jacob, B. Dix, T. K. Koenig, R. Sinreich, I. Ortega, R. Volkamer, A. Saiz-Lopez, C. PradosRoman, A. S. Mahajan and C. Ordóñez, Atmos. Chem. Phys., 2016, 16, 12239-12271.

6 T. Sherwen, M. J. Evans, L. J. Carpenter, J. A. Schmidt and L. J. Mickely, Atmos. Chem. Phys., 2017, 17, 1557-1569.

7 B. Newsome and M. Evans, Atmos. Chem. Phys. Discuss., DOI: 10.5194/acp-2017-12.

8 A. K. Luhar, I. E. Galbally, M. T. Woodhouse, and M. Thatcher, Atmos. Chem. Phys., 2017, 17, 3749-3767.

9 T. Sherwen, M. J. Evans, L. J. Carpenter, J. A. Schmidt and L. J. Mickley, Halogen chemistry reduces tropospheric $\mathrm{O}_{3}$ radiative forcing, Atmos. Chem. Phys., 2017, 17, 1557-1569, DOI: 10.5194/acp-17-1557-2017.

Eloise Marais questioned: How confident are you in the model's representation of $\mathrm{NO}_{x}$ surface emissions for estimating ozone in the base (no halogens) simulation?

Tomás Sherwen replied: Our work here is not unique. Our simulation is built on top of version 10-01 of GEOS-Chem, which has been used extensively for science elsewhere. There are obviously significant uncertainties in the emissions of $\mathrm{NO}_{x}$ and other $\mathrm{O}_{3}$ precursors. We note that even for London the $\mathrm{NO}_{x}$ emissions are uncertain to a factor of $\sim 2 .{ }^{1}$ This obviously imposes a significant uncertainty on our calculations but these are hurdles that all models face.

1 A. R. Vaughan et al., Faraday Discuss., 2016, 189, 455.

Dwayne Heard communicated: I'd like to make a comment regarding the recent paper by Bannan et al. ${ }^{1}$ concerning the impact of chlorine atom chemistry in central London during ClearFlo in 2012, in which the oxidation of VOCs by reaction with $\mathrm{Cl}$ atoms (modelled from measured $\mathrm{ClNO}_{2}$ ), $\mathrm{OH}$ radicals (measured) and $\mathrm{O}_{3}$ (measured) were compared. For the day when $\mathrm{Cl}$ atoms were modelled to be at a maximum (the day after the maximum mixing ratios of $\mathrm{ClNO}_{2}$ were observed during the night), $\mathrm{Cl}$ atoms dominated the oxidation of alkanes in the early morning. The \% removed by $\mathrm{Cl}$ atoms averaged over the whole of this day were: Alkanes (15\%), Alkenes (3\%) and Alkynes (26\%). These can be compared with the average removal by $\mathrm{Cl}$ atoms for the whole ClearFlo campaign which was Alkanes (3.7\%), Alkenes (0.66\%) and Alkynes (7.4\%). The average alkane \% value is smaller than the value in your present paper given for ethane $(12 \%)$ and propane $(9.1 \%)$, but this might be expected as $\mathrm{Cl}$ atoms may be expected to play a smaller role than other oxidants in urban centres compared to the average for the European boundary layer.

1 T. J. Bannan et al., J. Geophys. Res.: Atmos., 2015, 120, 5638-5657. 
Tomás Sherwen replied: Thank you for your comment with more comparisons of reported removal of VOCs by $\mathrm{Cl}$ in London. The values we present are averaged throughout the boundary layer and therefore represent a regional scale that includes rural and urban airmasses, rather than solely urban, so cannot readily be compared to those at a single site in London. There are some forces occurring here. The relationship between $\mathrm{Cl}$ oxidation and $\mathrm{NO}_{x}$ are not completely clear. As $\mathrm{NO}$ concentrations increase it seems likely that $\mathrm{N}_{2} \mathrm{O}_{5}$ and so $\mathrm{ClNO}_{2}$ concentrations are likely limited by the rate of production of $\mathrm{NO}_{3}$ and thus $\mathrm{O}_{3}$ and $\mathrm{NO}_{2}$. Just as for $\mathrm{OH}$, it seems likely that the response of $\mathrm{ClNO}_{2}$ and thus $\mathrm{Cl}$ in urban environments is likely a nonlinear function of $\mathrm{NO}_{x}$ emissions. When considering the relative oxidation of urban VOCs by $\mathrm{Cl}$ and $\mathrm{OH}$ as a function of $\mathrm{NO}_{x}$ emissions/ concentration it is not at all obvious how that responds and a box model may be appropriate to explore the relative contributions processes further.

Nick Hewitt opened a discussion of the paper by Catherine Scott and asked: Did you include global temperature change since 1850 in your model runs?

Catherine Scott replied: Thank you for your question. Yes, the biogenic emissions are calculated using the Community Land Model which is being driven by observationally derived meteorology, including temperature. This means that our comparison is between a present day in which the land cover distribution is as it was in the year 2000 (approximately), and a present day in which land cover is held fixed to an 1850 distribution of PFTs, but those PFTs are existing in a presentday climate (and therefore emissions from the vegetation are driven by presentday temperature).

Alexander Archibald said: A really nice paper - thanks for your contribution. I guess my main question relates to the large changes you simulate in ozone. We've shown in a number of papers that isoprene chemistry is complex and the response of ozone depends a lot on the mechanistic details. ${ }^{1-3}$ How big an impact do you think this uncertainty would have? Do you think there are priorities for isoprene chemistry in terms of the ozone response e.g. in getting $\mathrm{PAN} / \mathrm{RONO}_{2}$ yields "right"?

1 A. T. Archibald et al., Atmos. Chem. Phys., 2010, 10, 8097-8118.

2 A. T. Archibald, M. E. Jenkin and D. E. Shallcross, Atmos. Environ., 2010, 44, 5356-5364.

3 O. J. Squire et al., Atmos. Chem. Phys., 2015, 15, 5123-5143.

Catherine Scott replied: Thanks for your comment and question. This is a very good point, and not something we really explore (the complexities of the VOC oxidation chemistry) in this study. The largest (zonal annual mean) changes we see in ozone concentration are in the tropical upper troposphere due to the efficient convective transport of air masses containing $\mathrm{O}_{3}$ precursors (in this case the products of VOC oxidation, particularly isoprene). This is consistent with other work we have done (currently under review) to explore the impact of complete deforestation on BVOC emissions, and therefore ozone concentrations. For complete, idealised, tropical deforestation we simulate a reduction in zonal annual mean ozone concentration of up to $20 \mathrm{ppb}$ in the tropics at around $200 \mathrm{hPa}$. This region (tropical upper troposphere) is also the most important 
region radiatively in terms of changes to $\mathrm{O}_{3}$ concentration (e.g., Rap et al. ${ }^{1}$ ), so processes that lead to the changes in $\mathrm{O}_{3}$ here are particularly important to get right when diagnosing climate impacts.

In terms of surface $\mathrm{O}_{3}$ changes, these are sensitive not only to the magnitude of the change in BVOC emission, but whether the region is $\mathrm{NO}_{x}$ or VOC limited. As highlighted by Squire et al., ${ }^{2}$ the same change in isoprene emission (for example, due to LUC) can lead to different responses in surface $\mathrm{O}_{3}$ for the same location when different chemical mechanisms are applied. In particular the study highlighted that the sign of the change of $\mathrm{O}_{3}$ can be reversed in models that do not include PAN production as a result of isoprene chemistry. Improving our knowledge of isoprene oxidation chemistry in the atmosphere (for example, in terms of product yields) will be vital in order to accurately diagnose the impacts of BVOC emission changes on ozone, but also for improving our representation of secondary organic aerosol formation.

1 A. Rap, N. A. D. Richards, P. M. Forster, S. A. Monks, S. R. Arnold and M. P. Chipperfield, Geophys. Res. Lett., 2015, 42, 5074-5081.

2 O. J. Squire et al., Atmos. Chem. Phys., 2015, 15, 5123-5143.

Nadine Unger asked: How well do we understand the interactions between biogenic organic aerosol and different cloud types and how are those interactions represented in your model?

Catherine Scott responded: In our model, we explore the change to cloud droplet number concentrations in low- and mid-level clouds (below $600 \mathrm{hPa}$ ). Diagnosing the change in cloud droplet number concentration requires some assumptions to be made about the hygroscopicity of different components in the aerosol. We use the approach of Petters and Kreidenweis ${ }^{1}$ and calculate a volume weighted hygroscopicity parameter $(\kappa)$ to reflect the composition of the aerosol in each mode. There is substantial uncertainty associated with the hygroscopicity of organic material observed in the atmosphere, and it is clearly a simplification to apply a single $\kappa$ value to the wide range of compounds that make up the organic fraction of atmospheric aerosol. We assign a $\kappa$ value of 0.1 to the particulate organic material in our model, a value which has been reported from measurements of organic aerosol produced from VOC oxidation.

1 M. D. Petters and S. M. Kreidenweis, Atmos. Chem. Phys., 2007, 7, 1961-1971.

Nadine Unger then asked: Would you be confident in discussing your biogenic aerosol-cloud radiative forcing result with policy-makers?

Catherine Scott replied: Thank you for the question. When discussing any of the radiative forcings associated with changes to SLCFs (due in this case to historical land use change) with policy makers, I would be keen to stress that currently global chemistry-climate models/Earth System Models do not agree on the sign/strength of all of these changes and that we are still learning more about the role of biogenic VOCs in both the gas and particle phase. The biogenic aerosol-cloud RF is a good example, I think we can be confident that the oxidation of both monoterpenes and isoprene (and other VOCs) produces a variety of products with a range of volatilities and that some of these compounds play key 
roles in the formation and growth of particles in the atmosphere. In the model we use here (the GLOMAP aerosol microphysics model), by enabling the growth of particles up to the size at which they are able to act as cloud condensation nuclei (CCN), the presence of biogenic SOA exerts an overall negative radiative effect through the aerosol indirect effect. Other models simulate the distribution of the oxidised organic material across the size distribution differently - we examined the impact of a "kinetic" vs "mass-based" approach to distributing organic material $^{1}$ and found that this is an important control on the strength of the aerosol indirect effect due to biogenic SOA. Additionally, changes to CCN concentration also depend on the baseline aerosol size distribution that is being perturbed. In some situations, the addition of extra SOA will grow existing CCNsized particles to a larger size (regardless of the method used to distribute the SOA across the size dist) and the result is that fewer particles will activate. So understanding the role of biogenic SOA also requires an accurate representation of everything else that influences the aerosol size distribution.

1 C. E. Scott, D. V. Spracklen, J. R. Pierce, I. Riipinen, S. D. D’Andrea, A. Rap, K. S. Carslaw, P. M. Forster, P. Artaxo, M. Kulmala, L. V. Rizzo, E. Swietlicki, G. W. Mann and K. J. Pringle, Atmos. Chem. Phys., 2015, 15, 12989-13001.

Astrid Kiendler-Scharr remarked: The land use change described by you will likely also affect $\mathrm{NH}_{3}$ emissions, which should induce changes in the formation of ammonium sulfate and ammonium nitrate aerosol. Have you assessed the radiative forcing associated with such chenges in $\mathrm{NH}_{3}$ emissions?

Catherine Scott responded: Thank you for your comment. Here we have focused on the impacts (on short lived climate forcers) associated with changes in the emission of biogenic volatile organic compounds specifically. We don't address the changes to formation of ammonium sulphate and ammonium nitrate here but this is a priority for us in terms of evaluating the impacts of land use change more broadly. Heald and Geddes ${ }^{1}$ simulate a negative radiative forcing $\left(-0.071 \mathrm{~W} \mathrm{~m}^{-2}\right)$ associated with the increase in nitrate aerosol formed due to agricultural emissions of ammonia and soil $\mathrm{NO}_{x}$ in the present day, when compared to 1850. This negative forcing outweighed the positive forcing associated with their simulated reduction in biogenic secondary organic aerosol; highlighting the importance of understanding the magnitude of these (radiatively) opposing effects.

1 C. L. Heald and J. A. Geddes, Atmos. Chem. Phys., 2016, 16, 14997-15010.

Tim Wallington asked: In Fig. 7 of your paper you present the global mean radiative forcing for changes in SLCP due to changes in biogenic emissions associated with LUC between 1850 and 2010. The net effect is approximately 5 $\mathrm{mW} \mathrm{m}{ }^{-2}$. How does this compare with the direct effect of surface albedo changes associated with LUC? I didn't see a discussion of this in your paper, it might be useful to expand on this to provide context to the results presented in your paper.

Catherine Scott responded: Whilst we do not calculate this explicitly for our LUC scenario, the IPCC Fifth Assessment Report ${ }^{1}$ gives a best estimate of $-0.15 \mathrm{~W}$ $\mathrm{m}^{-2}$ (range -0.05 to $-0.25 \mathrm{~W} \mathrm{~m}^{-2}$ ) for the surface albedo radiative forcing associated with land-use change between 1750 and 2011. This suggests that our 
total (DRE and AIE) aerosol effect $\left(+0.033 \mathrm{~W} \mathrm{~m}^{-2}\right)$ is around $22 \%$ of the strength of the surface albedo RF (and of the opposite sign), and our total $\left(\mathrm{O}_{3}+\mathrm{CH}_{4}\right)$ gasphase effect $\left(-0.027 \mathrm{~W} \mathrm{~m}^{-2}\right)$ is around $18 \%$ of the strength of the surface albedo effect (and of the same sign). The small positive RE obtained from combining our SLCFs is then around 3\% of the strength of the albedo effect.

1 G. Myhre, D. Shindell, F.-M. Bréon, W. Collins, J. Fuglestvedt, J. Huang, D. Koch, J.-F. Lamarque, D. Lee, B. Mendoza, T. Nakajima, A. Robock, G. Stephens, T. Takemura and H. Zhang, 'Anthropogenic and Natural Radiative Forcing', in Climate Change 2013: The Physical Science Basis. Contribution of Working Group I to the Fifth Assessment Report of the Intergovernmental Panel on Climate Change, ed. T. F Stocker, D. Qin, G.-K. Plattner, M. Tignor, S. K. Allen, J. Boschung, A. Nauels, Y. Xia, V. Bex and P. M. Midgley, Cambridge University Press, Cambridge, United Kingdom and New York, NY, USA, 2013.

William Collins remarked: There is information available on the crops that have been planted and their isoprene and monoterpene emission characteristics. Have you thought of using this, rather than the generic "grass" PFT? This might make a difference for instance in Borneo where the main crop is oil palm which has much higher isoprene emissions than grass.

Catherine Scott replied: Thank you for your comment. During the time period we have examined here (1850-2000) the dominant transition in Borneo (for example) is from broadleaf trees to crops, as shown in Fig. 2 in our manuscript. Here we have used the emission characteristics assumed by MEGANv2.1, within the Community Land Model, for the "crop" PFT. Table 2 of Guenther et al. $(2012)^{1}$ provides the global average (area weighted across different regions) emission factors for all PFTs. The global average isoprene emission factor for the crop PFT is very low $\left(1 \mu \mathrm{g} \mathrm{m}^{-3}\right)$, but the emission factors (per PFT) do vary regionally in an attempt to account for the many species that may be included within a single PFT (Guenther et al., 2012). We have not yet fully explored the representativeness of these values, in terms of present day land cover, and the impact this has on our results - but this will be an important next step.

1 A. B. Guenther, et al., The Model of Emissions of Gases and Aerosols from Nature version 2.1 (MEGAN2.1): an extended and updated framework for modelling biogenic emissions, Geosci. Model Dev., 2012, 5(6), 1471-1492.

Paul Young remarked: The impact of BVOCs on SLCFs will be dependent on the chemical environment they are emitted into. Your model simulations used anthropogenic emissions for the year 2000, and this will likely play a large role in the size of impact that you determine for the changing BVOCs. How different would the impact be when using, say, pre-industrial anthropogenic emissions? Furthermore, do you have any thoughts on the "right" way to calculate/report impacts for these kinds of experiments?

Catherine Scott answered: Thank you for your question - yes the anthropogenic emissions that we assumed (in this case for the year 2000) will have an impact on the magnitude of the radiative effects we diagnose for the changes in SLCFs. We have shown previously that the strength of the aerosol indirect effect associated with natural aerosol ${ }^{1}$ and biogenic SOA in particular ${ }^{2}$ is sensitive to the anthropogenic emissions assumed in a simulation (with a stronger negative AIE 
simulated in the absence of anthropogenic emissions). The direct radiative effect due to natural aerosol/biogenic SOA is less sensitive to the anthropogenic emissions used as this tends to scale more linearly with the mass of aerosol being added to the atmosphere, in the GLOMAP aerosol microphysics model. ${ }^{2,3}$ These analyses assumed a much cleaner pre-industrial atmosphere (as compared to the present day), but there is still substantial uncertainty around the level and spatial extent of fires in the pre-industrial period.

In the gas-phase, $\mathrm{NO}_{x}$ concentrations will determine whether changes to VOC emission lead to an increase or decrease in ozone concentration. Heald and Geddes $^{4}$ found that the reduction in ozone due to historical LUC was around $35 \%$ greater when they assumed year 2000 anthropogenic emissions, as compared to a simulation in which anthropogenic emissions for the year 1850 were used. Assuming that we were to find the same response for ozone, this suggests that if we had used pre-industrial anthropogenic emissions - we would have simulated a larger (positive) aerosol indirect effect, similar direct radiative effect and a smaller (negative) ozone radiative effect.

1 D. V. Spracklen and A. Rap, Geophys. Res. Lett., 2013, 40, 5316-5319.

2 C. E. Scott, A. Rap, D. V. Spracklen, P. M. Forster, K. S. Carslaw, G. W. Mann, K. J. Pringle, N. Kivekäs, M. Kulmala, H. Lihavainen and P. Tunved, Atmos. Chem. Phys., 2014, 14, 447470.

3 A. Rap, C. E. Scott, D. V. Spracklen, N. Bellouin, P. M. Forster, K. S. Carslaw, A. Schmidt and G. Mann, Geophys. Res. Lett., 2013, 40, 3297-3301.

4 C. L. Heald and J. A. Geddes, Atmos. Chem. Phys., 2016, 16, 14997-15010.

Tomás Sherwen asked: My question is on the ozone budget in your model. The average ozone in ACCMIP models ${ }^{1}$ is $\sim 20 \%$ higher $\left(337( \pm 23) \mathrm{Tg} \mathrm{O}_{3}\right.$ ). Could you comment on the ozone simulation in your model? Due to lower oxidant mixing ratios, would you therefore expect your reported impacts (e.g., SOA) to be underestimated?

1 P. J. Young et al., Atmos. Chem. Phys., 2013, 13, 2063-2090.

Catherine Scott responded: Thanks for your question. Yes the tropospheric ozone burden we simulate here (approximately $290 \mathrm{Tg} \mathrm{O}_{3}$ ) is lower than the range reported across the ACCMIP models - we are currently reviewing the reasons for this. As you point out, a level of ozone that is too low will affect the amount of oxidation occuring and the formation of secondary organic oxidation products.

We assume a fixed molar yield of $13 \%$ for the production of a secondary organic gas-phase condensable species from the oxidation of monoterpenes, and a molar yield of $3 \%$ for the production of a secondary organic gas-phase condensable species from the oxidation of isoprene. In our year 2000 simulation that assumes present-day land cover, we simulate an emission of $453 \mathrm{Tg}$ isoprene $\mathrm{yr}^{-1}$ and $161 \mathrm{Tg}$ monoterpene $\mathrm{yr}^{-1}$, and produce approximately $15 \mathrm{Tg}$ SOA $\mathrm{yr}^{-1}$ from isoprene and $22 \mathrm{Tg}$ SOA $\mathrm{yr}^{-1}$ from monoterpene oxidation. These values are consistent with molar yields of $3 \%$ and $13 \%$ for isoprene and monoterpene oxidation, respectively, at the appropriate molecular weights - so we can be reasonably confident that we are not limiting the ability of SOA precursors to oxidise (at the global annual mean level). Our simulated reduction in global annual total BVOC emissions (of 13\%) due to land cover change between the years 1850 and 2000 carries through to a $13 \%$ reduction in global annual SOA 
production. However we will continue to investigate the causes and impacts of the low ozone burden in this particular model version.

Jonathan Williams addressed Christian George: Following up on Astrid's earlier question, presently isoprene in human breath is thought to be a byproduct of the synthesis of natural cholesterol. Have you perhaps measured cholesterol in your liquid phase analyses?

Christian George replied: The liquid phase analysis by LC-MS did not give any signals for cholesterol. Moreover, to the best of our knowledge cholesterol is more common to animal life than to plants or microorganisms. Nonetheless, it should be noted that our measurement setup was not specifically designed for the detection of this compound. Thus, we cannot exclude the presence of small amounts of cholesterol in the samples. In general, for microalgae and bacteria, two pathways of isoprene production are known: the mevalonate pathway (e.g., for archaea, few bacteria and eukaryotes) and the methylerythritol phosphate pathway (e.g., for green algae and most bacteria). ${ }^{1,2}$

1 J. Paniagua-Michel et al., Meth. Mol. Biol., 2012, DOI: 10.1007/978-1-61779-879-5_1. 2 S. S. Chandran et al., Proc. Biochem., 2011, DOI: 10.1016/j.procbio.2011.05.012.

A. Ravishankara opened a general discussion of the papers by Christian George, Tomás Sherwen and Catherine Scott: Thank you for your three interesting papers. In looking at each of your papers, a couple of questions come up. First, what is the key thing one can think about going backwards or going forwards based on the work you presented? Currently we are already in the Anthropocene and I assume that the goal of humanity is to leave this epoch into a more a sustainable age. Therefore, what do you see is important in your area to enable us to get away from major human influences?

Christian George responded: First, as explained in an answer to an earlier question from Alexander Archibald, our results describe photochemical processes in the ambient environment that are not limited to the Anthropocene. However, these interfacial reactions are certainly altered or even enhanced by anthropogenic activities. For example, nutrients from agriculture stimulate growth of microorganisms and algae in coastal waters which eventually increases surfactant concentrations at the air/water interface. Nonetheless, up to now our results indicate that VOC emissions from interfacial photochemistry are especially important in remote regions of the oceans. In these locations anthropogenic influences are believed to be rather small yet. However, changes in surfactant concentrations due to human activities would, thus, have the largest impact on interfacial photochemical VOC production and, hence, also on atmospheric chemistry especially in such remote regions. The second question is difficult as further studies will be needed to quantify the extent of anthropogenic influences on photochemical VOC production at the air/water interface. Therefore, it is difficult to give an answer at this point on how to reduce human influences on these photochemical processes, but in general, humans will have to further reduce their fingerprint on this planet by reducing emissions. 
Tomás Sherwen answered: One point here is that there is a tendency to think about environmental problems as discrete separate problems. The stratospheric ozone hole and tropospheric ozone production are separate problems which need separate modelling tools to understand them. In reality many of these problems are linked. For example from our work we have shown that the co-release of halogenated compounds (whether they decompose in the troposphere or in the stratosphere) with photo-pollutants (VOC, $\mathrm{CO}, \mathrm{NO}_{x}$ etc.) ultimately leads to a reduction in the total production of ozone pollution by those photo-pollutants. ${ }^{1-3}$ Moving to a more Earth system science perspective on atmospheric chemistry will allow us to understand in a more holistic sense what the impacts of humanity are on the atmosphere.

1 T. Sherwen, M. J. Evans, L. J. Carpenter, J. A. Schmidt and L. J. Mickley, Halogen chemistry reduces tropospheric O3 radiative forcing, Atmos. Chem. Phys., 2017, 17, 1557-1569, DOI: 10.5194/acp-17-1557-2017.

2 T. Sherwen, J. A. Schmidt, M. J. Evans, L. J. Carpenter, K. Großmann, S. D. Eastham, D. J. Jacob, B. Dix, T. K. Koenig, R. Sinreich, I. Ortega, R. Volkamer, A. Saiz-Lopez, C. PradosRoman, A. S. Mahajan and C. Ordóñez, Atmos. Chem. Phys., 2016, 16, 12239-12271.

3 J. A. Schmidt, D. J. Jacob, H. M. Horowitz, L. Hu, T. Sherwen, M. J. Evans, Q. Liang, R. M. Suleiman, D. E. Oram, M. L. Breton, C. J. Percival, S. Wang, B. Dix and R. Volkamer, J. Geophys. Res.: Atmos., 2016, 121, 11819-11835.

Catherine Scott responded: We show in our paper (and others have before) that historical land use change has not just had an impact on terrestrial carbon storage and the reflectivity of the surface, but also the composition of the atmosphere. We find that for LUC between 1850 and 2000, the gas-phase and aerosol radiative impacts (examined in our paper) almost cancel out. The way that landuse changes over the next century will depend strongly on society's response to the threat of climate change. For example, the four Representative Concentration Pathways (RCPs) each assume a very different land cover transition over time, in terms of forest and crop area and how the two link to food production and energy generation. To enable humanity to develop sustainably we will need to further understand the complex impacts that LUC has on the atmosphere, and ensure that we are not acting in a way that exacerbates future warming.

Lucy Carpenter addressed Christian George: I think an important question is how to disaggregate any surface ocean emissions, providing evidence for these mechanisms, from the more well known and characterised emissions from sub surface (mainly biological) production. One way to do that is to compare eddy co-variance measurements from ships with bottom up fluxes inferred from bulk seawater. That has been done for some of the OVOCs (e.g., acetone) proposed as products of this surface chemistry (M. Yang et al., 2014, ref. 1), which I believe shows that if anything there could be a loss of acetone at the surface. Is there other evidence for surface sources, or do you believe that the uncertainties involved leave room for them?

1 M. Yang, B. W. Blomquist and P. D. Nightingale, Air-sea exchange of methanol and acetone during HiWinGS: Estimation of air phase, water phase gas transfer velocities, J. Geophys. Res.: Oceans, 2014, 119, DOI: 10.1002/2014JC010227.

Christian George responded: We agree that up to now field observations of VOC emissions from interfacial photochemistry are scarce. One major challenge here is certainly to distinguish biological and photochemical VOC production. 
Nonetheless, a promising approach was recently published by Mungall et al. ${ }^{1}$ In this study, factor analysis was applied to shipboard measurements of an HR-ToFCIMS and an 'ocean factor' was isolated, comprising several signals for OVOCs. A comparison of this factor with data for solar radiation, dissolved organic carbon (DOC), and fluorescent chromophoric dissolved organic matter (fCDOM), combined with retroplume analysis and wind speed measurements, indicated that the source of this 'ocean factor' was likely interfacial photochemistry occurring at the sea surface microlayer.

1 E. L. Mungall et al., Proc. Natl. Acad. Sci. U. S. A., 2017, 114, 6203-6208.

Alla Zelenyuk commented: You emphasized the importance of surface photochemistry of biofilms that are similar to those that are found on ocean/air interfaces, as a source of atmospheric VOC. Do you expect that surfactantcoated marine aerosols can significantly contribute to VOC production given their large surface-to-volume ratios?

Christian George responded: Depending on composition, morphology and phase state, organic aerosol particles, and also cloud droplets, might indeed exhibit similar VOC emissions due to interfacial photochemistry of surfactants and, thus, contribute to ambient VOC levels. However, to confirm this hypothesis further studies will be needed.

Frank Keutsch opened discussion of the paper by Nadine Unger: It could be useful to discuss/show not only precipitation changes but also (precipitation evaporation) when discussing drying. In this context, it would be helpful to discuss what exactly is meant with "drying", e.g., what metric is the most meaningful for ecosystems $v s$. atmospheric humidity etc.

Nadine Unger replied: Because the aerosol-induced southward shift in the ITCZ (into the warmer hemisphere) is an important component of the aerosol climate impacts on tropical ecosystems, and to facilitate comparison with the inspirational study of Wang et al., ${ }^{2}$ it is essential for this study to show the spatial plots of precipitation changes only. We certainly do agree that it is a great idea for future follow-up analysis work to investigate $(P-E)$ changes for the different aerosol climate change cases. In the current version of NASA ModelE2-YIBs, the net water flux into the surface $-P-E$ over the ocean - is available in the output diagnostics, while $P-E$ over land is not available in the output. In future work, we will add this variable as a model standard diagnostic (e.g., Byrne and O'Gorman ${ }^{1}$ ).

1 M. P. Byrne and P. A. O’Gorman, J. Climate, 2015, DOI: 10.1175/JCLI-D-15-0369.1.

2 C. Wang, Anthropogenic aerosols and the distribution of past large-scale precipitation change, Geophys. Res. Lett., 2015, 42, 10876-10884.

Stephen Arnold said: I wanted to ask about your assumption about fires being anthropogenic. The "aerosol-free" world may not be an analogue for preindustrial if some fires are natural. Does this have implications for your conclusions if not all fires can be attributed to anthropogenic activity? 
Nadine Unger answered: Our goal is that the "anthropogenic pollution aerosolfree" world represents the global climatic state that we would be living in now without the historical rise in anthropogenic aerosol pollution (i.e., a warmer, wetter world). We are not interested in pre-industrial (i.e., colder, drier) analogues. You raise an important question about biomass burning aerosol emissions. Firstly, what were the pre-industrial fire emissions and what is pre-industrial? These questions are very difficult (almost impossible) to answer with available measurement/ observational data. In this study, we assigned all biomass burning emissions to be anthropogenic because, in the present day climatic state, it becomes increasingly challenging to define exactly what is human-influenced fire activity and what is not. Deforestation and land-clearing fire aerosol emissions (which are the dominant fraction at the global-scale), are unambiguously anthropogenic. Wildfire aerosol is less clear cut, for instance, if wildfire emissions have been human-modified in some way, e.g. by anthropogenic climate change, human land use land cover change, and/ or human fire suppression/ignition, then which category do they fall into exactly? We apply a global gridded inventory that separates 2 fire sources: "forest fire" deforestation and land clearing; "grassfire" wildland fire. I have some concerns that the aerosol impact results over central west Africa are the least "anthropogenic" of all our findings. Because the largest aerosol climate impacts found in the Amazon and North American boreal zones are strongly dominated by the global-scale cooling (mediated through ocean feedbacks), driven by the $\mathrm{NH}$ mid-latitude pollution band, I argue that our major conclusions are relatively insensitive to the biomass burning aerosol categorization. That said, it would be interesting in future experiments to include only "forest fire" aerosol emissions as anthropogenic, and compare with results here. We could even potentially begin to think about an historical loss of wildfire (and aerosol emissions) occurring in the temperate zone due to human land use and land cover change that precedes the $\mathrm{NH}$ mid-latitudes aerosol pollution band from the fossil-fuel/energy revolution. A further distinction is that fire regimes tend to be sporadic in nature, and have much larger spatiotemporal variability that aerosol emissions from fossil fuel, energy and agricultural activities.

Andreas Petzold asked: How have you defined the aerosol load for the preindustrial case? In this period the atmosphere was not aerosol free, but contained natural aerosol. In order to get cloud cover right also for the pre-industrial case, you have to assume a certain aerosol background.

Nadine Unger replied: The study does not have any "pre-industrial case". The contemporary decadal average world in 1996-2005 is contrasted with the global climatic state that would exist in this decade in the absence of the historical rise in anthropogenic aerosol pollution (a warmer, wetter world). In the manuscript, "aerosol-free" means "anthropogenic pollution aerosol-free". In our global model framework, the natural aerosol background includes dust, sea salt, sulfate, nitrate, ammonium, and SOA particles. Secondary aerosols are simulated interactively from climate sensitive precursor emissions including $\mathrm{NO}_{x}$ from soils and lightning, $\mathrm{NH}_{3}$ and DMS from oceans, and BVOCs from vegetation (e.g., Schmidt et al. ${ }^{1}$ ).

It is important to recognize that our study does not contrast the contemporary climatic state with the pre-industrial (the results shown are not impacts relative to the pre-industrial), but instead we contrast with the hotter and wetter reality that we would be living in now without the historical rise in anthropogenic aerosol pollution. 
Andreas Petzold queried: You turn off anthropogenic emissions - but you need aerosols for generating clouds and rain. What do you assume about the natural sources of aerosols?

Nadine Unger answered: In our NASA ModelE2-YIBs framework, the natural aerosol background includes dust, sea salt, sulfate, nitrate, ammonium, and SOA particles. Secondary aerosols are simulated interactively from climate sensitive precursor emissions including $\mathrm{NO}_{x}$ from soils and lightning, $\mathrm{NH}_{3}$ and $\mathrm{DMS}$ from oceans, and BVOCs from vegetation (e.g., Schmidt et al. $\left.{ }^{1}\right)$. Thus, the model does represent dynamic natural aerosol-climate feedbacks in the Earth system, but the total global forcing is always dominated by the anthropogenic aerosol changes.

1 G. A. Schmidt et al., J. Adv. Model. Earth Syst., 2014, 6, 141-184.

Drew Shindell said: Over the past few decades we have done some things with power plants, e.g. scrubbers, that primarily affect aerosols (and ozone) but not the long-lived greenhouse gases. If we move to clean power sources and other practical ways we might change emissions in the future, would the simultaneous greenhouse gas changes cancel out the aerosol-related effects you discuss?

Nadine Unger responded: To some extent, yes. The "AEROSOL-OCEAN" feedback components in the regional response signals effectively give us quantitative information about aerosol forcing increases and/or GHG forcing decreases in the Earth system. However, examination of the "AEROSOL-LAND" case tells us that the aerosol climate change effects on land ecosystems are not exactly simply equivalent to the reverse of the carbon-climate feedbacks shown in IPCC AR5 Fig. 6.22. The aerosol forcing is concentrated over land regions and activates different land-atmosphere feedbacks than would an equivalent magnitude GHG forcing. Most simply put, aerosols are predominantly interacting with the downward SW, whereas GHGs are interacting with the LW. For instance, there is no GHG-equivalent to aerosol diffuse radiative fertilization. Concentrated aerosol forcing over land decreases SW radiation at the land surface that decreases surface evaporation and increases soil water availability in some areas but simultaneously decreases precipitation in other areas. In general, aerosol pollution impacts on regional precipitation patterns are not yet completely well understood, and are rather model dependent, but it is agreed that they will not be the simple reverse of the GHG spatial patterns (because modifying SW versus LW has different impacts on regional hydrology). In contrast, $\mathrm{CO}_{2}$ fertilizes the land biosphere leading to enhancements in NPP, "the carbon-concentration feedback"; and there is no equivalent/analogous aerosol impact. Aerosol deposition to the land surface can have biogeochemical effects on ecosystem health (e.g., adding nutrients or acidic toxins), but these effects are not assessed in this study that focuses on climate change. In summary, without performing fully coupled future simulations, it is not clear how future combined changes in aerosols, ozone and GHGs will influence the land biosphere and the land carbon sink. For instance, reducing GHGs and $\mathrm{CO}_{2}$ would, over decadal to century timescales, show a similar spatial pattern to "AEROSOL-OCEAN", but at the same time reduce 
$\mathrm{CO}_{2}$ fertilization benefits. As we head into the future, the aerosol forcing becomes increasingly much less important relative to the GHG and $\mathrm{CO}_{2}$ forcings. In other words, the protection of Amazon ecosystem health over the past 2-3 decades from inadvertent climate engineering with $\mathrm{NH}$ aerosol pollution has been an unintended transient benefit. Our analyses focus on annual average changes, which likely emphasizes temperature over precipitation. Future investigation of seasonal and monthly changes may reveal more important roles for aerosolinduced regional precipitation changes.

Alexander Archibald commented: This is a nice study. I just had a technical question: are ozone feedbacks on vegetation included in these simulations?

Nadine Unger responded: The simulations for this study did not include feedbacks from ozone vegetation damage. Our objective was to unravel the aerosol pollution climate change effects on land ecosystem functioning. In particular, what is the role of aerosol-induced global cooling relative to aerosol diffuse radiation fertilization in different biomes? Our global carbon-chemistryclimate model framework NASA ModelE2-YIBs does include interactive ozone vegetation damage using a flux-based algorithm. ${ }^{1,2}$ In a recently published study, we quantified the combined impacts of ozone and aerosol pollution on ecosystem health in China. ${ }^{3}$ In eastern China, in the present-day, ozone vegetation damage strongly dominates over aerosol effects and there is an annual net regional loss of NPP around $10 \%$. On-going projects in our group examine the combined impacts of ozone and aerosols on the land carbon cycle at the global-scale.

$1 \mathrm{X}$. Yue and $\mathrm{N}$. Unger, Ozone vegetation damage effects on gross primary productivity in the United States, Atmos. Chem. Phys., 2014, 14, 9137-9153.

$2 \mathrm{X}$. Yue and $\mathrm{N}$. Unger, The Yale Interactive terrestrial Biosphere model version 1.0: description, evaluation and implementation into NASA GISS ModelE2, Geosci. Model Dev., 2015, 8, 2399-2417.

3 X. Yue et al., Atmos. Chem. Phys., 2017, 17, 6073-6089.

Paul Young asked: Your presentation referred to fact that the climatic effects of anthropogenic aerosol have negated a large proportion of the greenhouse gas driven warming. Perverse as this would be, are you aware of any study that has quantified the health benefits of this "avoided" warming (e.g., avoided heat stress) versus the health dis-benefits from increased particulate matter reducing air quality? i.e., Can we say that, given the fact that we've increased greenhouse gas concentrations, aerosols have been a net positive contribution to human health? Obviously, this is perverse given that aerosols could only have had a positive effect given the other impacts that we have wrought on the climate system!

Nadine Unger answered: I prefer "masked" to "negated". Hansen famously called it "Humanity's Faustian climate bargain". Tropospheric aerosol pollution is inadvertent global and regional climate engineering that is and has been beneficial to tropical and temperate ecosystem health. As far as I know, the calculation that you propose has not been performed. I believe our study is the first ever to quantify effects of the aerosol global cooling (climate bargain) on regional ecosystem health. The human health effects calculations you suggest would provide a new provocative/controversial perspective on the value of the 
inadvertent aerosol climate engineering. Is it possible that we collaborate on this health effects calculation? Certainly, the model output including aerosol, climate, and meteorological fields are available to any colleagues wishing to perform the calculations. In particular, the data for the hypothetical warmer and wetter anthropogenic aerosol pollution-free world in 1996-2005.

Andreas Wahner opened discussion of the paper by Alla Zelenyuk: Does this trapping of PAHs in the SOA not shorten the atmospheric residence times of PAHs? Isn't there an enhanced removal process of PAHs from the atmosphere? PAHs are not water soluble but SOAs are, therefore by trapping the e.g. wash-out and deposition could be enhanced?

Alla Zelenyuk responded: We have recently developed a new modeling paradigm for long-range transport of particle-bound PAHs, in which PAHs are protected from evaporation and oxidation by highly viscous SOA. ${ }^{1}$ This new modeling approach was incorporated in a global climate model, which takes into account dry and wet aerosol deposition, with the latter taking into account aerosol size and hygroscopicity. We demonstrated that our new "SOA shielded" paradigm increases oxidation lifetime of benzo[a]pyrene (BaP), used as a PAH model system, from $2 \mathrm{~h}$ to 5 days. Most importantly, compared to previous models it predicts considerably higher BaP concentrations near urban sources and in remote locations, significantly improving agreement between model predictions and hundreds of field observations.

1 M. Shrivastava, S. Lou, A. Zelenyuk, R. C. Easter, R. A. Corley, B. D. Thrall, P. J. Rasch, J. D. Fast, S. L. Massey Simonich, H. Shen and S. Tao, Proc. Natl. Acad. Sci. U. S. A., 2017, 114, 1246-1251.

Steven Brown said: The result seems remarkable that such a small amount of $\mathrm{PAH}$ has such a large effect on SOA formation from a much larger concentration of VOC. At what level would this effect turn off? Even at 7 ppt you might be talking about a level that is higher than real situations, but if it were present at even lower concentrations it would be quite important. What about black carbon? Does it possibly have the same effect as a PAH?

Alla Zelenyuk replied: The vapor pressure of $\sim 7 \mathrm{ppt}$ for benzo[a]pyrene (BaP) represents the lowest $\mathrm{PAH}$ concentration investigated in the experiments thus far. The data clearly show that even at $7 \mathrm{ppt}$, it has a significant effect on SOA formation and properties. It is important to note that in many locations, especially close to the sources of biomass burning and power plants, the overall concentration of gas-phase PAHs often exceeds this level (e.g., Wang et al. ${ }^{1}$ and Galarneau et $a l^{2}{ }^{2}$ ). We agree, that given the low concentrations of reacted and unreacted PAHs acquired by SOA particles, their impact is surprisingly large. One possible explanation, suggested by Shiraiwa et al. ${ }^{3}$ is that long-lived ROIs can play important roles in heterogeneous ozonolysis of PAHs and affect SOA formation and properties. In their mechanism, the weakly bound physisorbed ozone molecule undergoes dissociation to form molecular oxygen and ROI, such as chemisorbed $\mathrm{O}$ atoms bound to the delocalized $\pi$-electrons of PAH aromatic surfaces. These long-lived ROIs may then form oxygenated PAHs or react with 
other chemical species, including those formed during oxidation of SOA precursors. The surface interactions of long-lived ROIs could also lead to the formation of multifunctional organic compounds, including oligomers, with high molecular weight and low vapor pressure, which are required for the nucleation and growth of new particles. We do not expect that black carbon particles will have the same effect as the PAHs presented here. We anticipate that the aromatic surfaces of black carbon will rapidly become coated by the condensing SOA and will no longer interact with ozone molecules. In contrast, in the experiments presented in this paper there is a steady source of gas-phase PAH molecules, which continue to adsorb on the surfaces of SOA particles throughout their formation and growth.

1 R. Wang, G. Liu and J. Zhang, Sci. Total Environ., 2015, 538, 180-190.

2 E. Galarneau, P. A. Makar, Q. Zheng, J. Narayan, J. Zhang, M. D. Moran, M. A. Bari, S. Pathela, A. Chen and R. Chlumsky, Atmos. Chem. Phys., 2014, 14, 4065-4077.

3 M. Shiraiwa, Y. Sosedova, A. Rouvière, H. Yang, Y. Zhang, J. P. D. Abbatt, M. Ammann and U. Pöschl, Nat. Chem., 2011, 3, 291-295.

Markus Kalberer asked: Could you please explain in more detail the possible reasons leading to the strong increased number concentrations in the experiments where PAHs are present? Could this point to a nucleation of PAHs, which would be an additional and independent process from the condensation on the SOA seeds discussed in the paper?

Alla Zelenyuk replied: As we state in the paper, the magnitude of the effects of PAHs on SOA formation that we observed in these studies is surprisingly large. To develop a comprehensive mechanistic understanding of the phenomenon requires further studies.

Given that in all the experiments PAHs were present at concentrations below their saturation vapor pressures, they cannot by themselves explain nucleation. A possible explanation, suggested by Shiraiwa et al., ${ }^{1}$ is that long-lived ROIs can play important roles in heterogeneous ozonolysis of PAHs and affect SOA formation and properties. In their mechanism, the weakly bound physisorbed ozone molecule undergoes dissociation to form molecular oxygen and ROI, such as chemisorbed $\mathrm{O}$ atoms bound to the delocalized $\pi$-electrons of PAH aromatic surfaces. These long-lived ROIs may then form oxygenated PAHs or react with other chemical species, including those formed during oxidation of SOA precursors. The surface interactions of long-lived ROIs could also lead to the formation of multifunctional organic compounds, including oligomers, with high molecular weight and low vapor pressure, which are required for the nucleation and growth of new particles.

1 M. Shiraiwa, Y. Sosedova, A. Rouvière, H. Yang, Y. Zhang, J. P. D. Abbatt, M. Ammann and U. Pöschl, Nat. Chem., 2011, 3, 291-295.

Christian George questioned: What type of condensed phase chemistry may take place after trapping the PAH? Can you quantify physical trapping versus chemical uptake?

Alla Zelenyuk answered: Our more recent observations indicate that SOA particles with trapped PAHs indeed can undergo further chemical transformations, 
including heterogeneous reactions with ozone and subsequent condensed-phase oligomerization leading to an increase in particle viscosity and the fraction of nearly non-volatile constituents, i.e. oligomers. The quantification of trapped unreacted and reacted PAHs in SOA particles during formation and growth is a focus of our ongoing studies that utilize real-time mass-spectrometric analysis as well as offline measurements of particles collected on filters. The preliminary data indicate that the concentrations of unreacted and reacted PAHs in the SOA particles depend on many variables, including the SOA precursors and their concentrations, ozone concentration, and the specific PAHs present and their concentrations.

Christian George then asked: You were mentioning that the PAHs are reacting on the surface with ozone, but could it also be that on your particles you have ROS being produced that may also chemically interact with the incoming PAH and thereby facilitate its trapping efficiency?

Alla Zelenyuk answered: Yes, it is possible. Shiraiwa et al. ${ }^{1}$ showed that longlived ROIs can play important roles in heterogeneous ozonolysis of PAHs. In their mechanism the weakly bound physisorbed ozone molecule undergoes dissociation to form molecular oxygen and ROI, such as chemisorbed $\mathrm{O}$ atoms bound to the delocalized $\pi$-electrons of PAH aromatic surfaces. These long-lived ROIs may then form oxygenated PAHs or react with other chemical species, including those formed during oxidation of SOA precursors. The surface interactions of long-lived ROIs could also lead to the formation of multifunctional organic compounds, including oligomers, with high molecular weight and low vapor pressure, which are required for the nucleation and growth of new particles.

1 M. Shiraiwa, Y. Sosedova, A. Rouvière, H. Yang, Y. Zhang, J. P. D. Abbatt, M. Ammann and U. Pöschl, Nat. Chem., 2011, 3, 291-295.

Barbara Finlayson-Pitts asked: First, you mention that pyrene oxidation products are trapped, in addition to pyrene itself. Do you have any idea of the relative contributions of pyrene and its oxidation products? Second, when you look at single particles, do you ever see separate individual particles primarily from either PAH or SOA, or are they always mixtures?

Alla Zelenyuk replied: The quantification of trapped unreacted and reacted PAHs acquired by SOA particles during formation and growth is part of ongoing research in our laboratory. Preliminary data indicate that concentrations of unreacted and reacted PAHs in the SOA particles depend on many parameters, including the specific PAH and its concentration, SOA formation and growth rate, ozone concertation, and more. However, just as an example, the preliminary results of filter analysis indicate that SOA particles formed by ozonolysis of $200 \mathrm{ppb}$ of $\alpha$-pinene formed in the presence of pyrene are composed of $\sim 1 \%$ pyrene, of which $\sim 20-30 \%$ has been oxidized. To answer the second question, single particle analysis indicates that all the particles are mixed, containing both SOA and PAHs.

Grazia Rovelli said: One of the main claims of the paper is that when SOA is formed in the presence of PAHs the degree of oligomerisation is increased which leads to an increase in viscosity and a decrease in the vapour pressure of the 
organic components formed. I have two questions related to this aspect. First, you always observe a decrease in volatilisation kinetics for SOA formed in the presence of PAHs, and this is attributed to increased viscosity and decreased average vapour pressure of the organics in the SOA. Do you have a feeling of which one of the two (either increased viscosity or decreased vapour pressure) is more important?

Secondly, on page 13 of your paper you measure a diffusion coefficient for pyrene within SOA and then you report a value of viscosity, which I assume is calculated with the Stokes-Einstein relation. Could you please confirm that this is how the viscosity value you present is calculated? In addition, this value of $2 \times 10^{7}$ Pa $\mathrm{s}$ for viscosity of $\alpha$-pinene SOA formed in the presence of PAHs does not seem to be significantly higher than what has been meassured for 'regular' $\alpha$-pinene SOA (see for example Maclean et al. ${ }^{1}$ ). In addition, Stokes-Einstein has been shown to be inaccurate for water and for larger molecules than pyrene at low relative humidity (see Chenyakin et $a .^{2}$ ). Since pyrene has a molecular weight that is somewhat in the middle between water and the paper that I reference here, don't you think that it is very likely that this viscosity value is incorrect, considering both the fact that it seems to contradict all the other results you have in your paper and possible inaccuracies of Stokes-Einstein?

1 A. Maclean et al., Atmos. Chem. Phys. Discuss., 2017, DOI: 10.5194/acp-2017-247, in review. 2 Y. Chenyakin et al., Atmos. Chem. Phys., 2017, 17, 2423-2435.

Alla Zelenyuk Our data, including those presented in this paper, clearly show that the presence of PAHs during SOA formation and growth increases SOA oligomer content. For example, Fig. $5 \mathrm{~b}$ shows that the mass spectra of $\alpha$-pinene SOA particles formed in the presence of pyrene ( $\alpha$ P-PY-SOA) exhibits increased relative intensity of peaks at high $\mathrm{m} / \mathrm{z}$, suggesting they contain more oligomers that have higher molecular weight and lower volatility, which agrees with the particle evaporation data shown in Fig. 2a.

To investigate the relative contributions of high particle viscosity and low volatility on SOA evaporation kinetics (i.e., the asymptotic value of the volume fraction remaining (VFR) after $\sim 24$ hours of evaporation) we compare the particle evaporation kinetics at low and high RH. We find, for example, that for pure $\alpha$ pinene SOA $(\alpha \mathrm{P}-\mathrm{SOA})$ an increase in $\mathrm{RH}$ from $<5 \%$ to $\sim 90 \%$ results in decrease in the asymptotic value of VFR from $25 \%$ to $20 \%$. For $\alpha$ P-PY-SOA particles the same change in $\mathrm{RH}$ results in the asymptotic value of VFR decreasing from $70 \%$ to $55 \%$.

In response to your second question, it is important to point out that most other studies determine SOA viscosity, which is then used to infer chemical diffusivity (the key property relevant to SOA phase), using the Stokes-Einstein equation (e.g., Shrivastava et al. $^{1}$ and references therein). As you point out, the diffusivity of small molecules, such as water, was reported to be orders of magnitude faster than that predicted by the Stokes-Einstein equation. Note that in our study, we directly measure diffusion and evaporation rates of pyrene in SOA particles from which we estimate viscosity. As we previously reported, the diffusivity of pyrene in $\alpha$ P-PY-SOA particles is $2.5 \times 10^{-21} \mathrm{~m}^{2} \mathrm{~s}^{-1}$, which yields an estimate of particle viscosity of $10^{8}$ Pa s (Abramson et al. ${ }^{2}$ ). The viscosity of $2 \times 10^{7} \mathrm{~Pa}$, you refer to in your question, is actually estimated for aged cyclooctene SOA particles formed in the presence of pyrene, which has lower viscosity than $\alpha$ P-PY-SOA. 
Measurements on aged $\alpha$ P-PY-SOA particles yield an estimated diffusivity $\sim 3$ times smaller, indicating that hardening occurs with time, which is consistent with the increase in SOA oligomer content, and decrease in evaporation rate observed with aging. There are no contradictions!

As far as comparison between our reported viscosities and other literature values, we refer to the measurements presented by Grayson et al. ${ }^{3}$ and used in the modeling paper cited by you above. For the range of SOA concentration we use, Grayson et al. (Fig. 3) report viscosity values in the range of $\sim 5 \times 10^{5} \mathrm{~Pa} \mathrm{~s}-2 \times 10^{7}$ Pa s. As they specifically state in their paper, our viscosity estimate is outside of their reported viscosity range, as it should be, given that our particles were made in the presence of pyrene.

Finally, we feel that it is also very important to look at "big picture" rather than focus on what we see as relatively small differences. All the reported values indicate that at low RH these particles are semi-solid and have viscosity million time higher than previously assumed.

1 M. Shrivastava, C. D. Cappa, J. Fan, A. H. Goldstein, A. B. Guenther, J. L. Jimenez, C. Kuang, A. Laskin, S. T. Martin, N. L. Ng, T. Petaja, J. R. Pierce, P. J. Rasch, P. Roldin, J. H. Seinfeld, J. Shilling, J. N. Smith, J. A. Thornton, R. Volkamer, J. Wang, D. R. Worsnop, R. A. Zaveri, A. Zelenyuk and Q. Zhang, Rev. Geophys., 2017, DOI: 10.1002/2016RG000540.

2 E. Abramson, D. Imre, J. Beranek, J. Wilson and A. Zelenyuk, Phys. Chem. Chem. Phys., 2013, 15, 2983-2991.

3 J. W. Grayson, Y. Zhang, A. Mutzel, L. Renbaum-Wolff, O. Böge, S. Kamal, H. Herrmann, S. T. Martin and A. K. Bertram, Atmos. Chem. Phys., 2016, 16, 6027-6040.

Jonathan Williams asked: Was there a difference in the efficiency of PAH uptake between smaller and larger PAH species?

Alla Zelenyuk replied: As mentioned earlier, the quantification of trapped unreacted and reacted PAHs acquired by SOA particles during formation and growth is a focus of our ongoing studies that utilize real-time mass-spectrometric analysis as well as the offline filter analysis. The preliminary data reveal a rather complex relationship between the observed concentrations of unreacted and reacted PAHs in SOA particles and PAH saturation vapor pressure (or its molecular weight). "The efficiency of PAH uptake", SOA formation, and particle properties, which include SOA volatility and viscosity, depend not only on the PAH molecule, but also on the SOA precursor and its concentration, as well as ozone concentration.

Liselotte Tinel communicated: What is the effect of $\mathrm{RH}$ on the absolute particle growth/number in presence of PY? I would have expected to see a decrease in uptake of this very apolar substance with increasing water content - but apparently still enough to provide a shielding effect. Could this be modelled?

Alla Zelenyuk communicated in reply: We agree that it is very important to investigate the effect of $\mathrm{RH}$ and temperature on SOA formation and growth and properties of SOA particles formed in presence of PAHs. In all the experiments presented in this paper SOA particles were formed under dry conditions. Nevertheless, as we briefly discussed in the paper, our preliminary data show that the effect of pyrene on the evaporation of SOA particles persists even at $\sim 90 \% \mathrm{RH}$. 
Jos Lelieveld opened a discussion of the paper by Daniel Knopf: The conclusion that anthropogenic aerosols are more effective ice nuclei is based on naphthalene - are you confident in extrapolating this to all anthropogenic SOA?

Daniel Knopf responded: Secondary organic aerosol (SOA) derived from anthropogenic precursor gases is not necessarily dominated by polycyclic aromatic hydrocarbons (PAHs). ${ }^{1}$ However, we do argue that anthropogenic SOA derived by PAHs with same and higher molecular weights should show similar properties in terms of glass transition and, thus, act as a solid substrate for ice nucleation under similar meteorological conditions. There is very limited data for anthropogenic SOA, derived from other precursor gases such as aliphatic compounds. Therefore, one may not extrapolate our findings to all types of anthropogenic SOA. One study calculated $T_{\mathrm{g}}$ and full deliquescence relative humidity (FDRH) for dodecane derived SOA particles at less favorable conditions to form ice than naphthalene derived SOA. ${ }^{2}$ However, ice nucleation has been observed to occur on organic and SOA dominated particles in general, collected in a polluted anthropogenic environment. ${ }^{3-5}$ The limited data available on the role of anthropogenic precursor gases in SOA formation and corresponding phase and ice nucleation propensity warrants further investigation. We hypothesize that if SOA derived from non-PAH precursor gases are not acting as ice nucleating particles, then $\mathrm{PAH}$ derived SOA may be especially important for cloud glaciation processes in anthropogenic environments dominated by SOA.

1 J. J. Schauer, W. F. Rogge, L. M. Hildemann, M. A. Mazurek and G. R. Cass, Atmos. Environ., 1996, 30, 3837-3855.

2 T. Berkemeier, M. Shiraiwa, U. Pöschl and T. Koop, Atmos. Chem. Phys., 2014, 14, 1251312531.

3 D. A. Knopf, P. A. Alpert, B. Wang, R. E. O’Brien, S. T. Kelly, A. Laskin, M. K. Gilles and R. C. Moffet, J. Geophys. Res., 2014, 119, 1-17.

4 B. B. Wang, A. Laskin, T. Roedel, M. K. Gilles, R. C. Moffet, A. V. Tivanski and D. A. Knopf, J. Geophys. Res., 2012, 117, D00V19.

5 D. A. Knopf, B. Wang, A. Laskin, R. C. Moffet and M. K. Gilles, Geophys. Res. Lett., 2010, 37, L11803.

Andreas Petzold commented: Thank you very much for this interesting data you have presented. I would like to hear more about the relevance of anthropogenically generated SOA for the formation of cold clouds. Usually, anthropogenically generated SOA are emitted near the ground. During lifting to higher altitudes they most likely go through the liquid phase before they freeze. Could you please elaborate on the atmospheric relevance of your results?

Daniel Knopf replied: When anthropogenic secondary organic aerosol (SOA) particles are lifted to higher altitudes, they experience increasing relative humidity (RH), supersaturation with respect to ice, and decreasing temperatures. During this process the particles can acquire water in the subsaturated regime until they reach water saturation. Our study optically detects if biogenic SOA or anthropogenic SOA coatings on soot, deliquesce completely or incompletely when going through the liquid phase. This can lead either to homogeneous or heterogeneous ice nucleation, respectively, the latter due to the presence of an insoluble or solid organic or soot particle. As described in the article, this will also depend on the updraft velocity. In the case of vertical air motion in clouds, the fast updrafts may result in high $\mathrm{RH}$ 
before full deliquescence occurs, especially important for highly viscous organic aerosol (OA). Our study emphasizes the interrelationship between ice nucleation and SOA phase state changes due to $\mathrm{RH}$ and temperature changes, which was also investigated by Berkemeier et al. ${ }^{1}$ Lienhard et al., ${ }^{2}$ and Price et al. ${ }^{3}$ Naphthalene SOA coated soot particles studied here formed ice at water saturation temperatures warmer than homogeneous freezing. One explanation for this is that the soot particles acted as ice nuclei (IN) after complete deliquescence of the thin SOA coating. However, a study by Wang et al. ${ }^{4}$ has shown that naphthalene SOA particles initiated ice formation at the same conditions, alternatively implying that there was remaining solid SOA present on the soot surface that initiated freezing within the surrounding liquid. SOA derived from higher molecular weight organic precursor gases may have higher $T_{\mathrm{g}}{ }^{5}$ and FDRH, and could result in a stronger propensity to act as IN despite the presence of a liquid phase. Clearly, more laboratory ice nucleation studies on anthropogenic SOA particles are needed to assess their role in cloud glaciation.

1 T. Berkemeier, M. Shiraiwa, U. Pöschl and T. Koop, Atmos. Chem. Phys., 2014, 14, 1251312531.

2 D. M. Lienhard, A. J. Huisman, U. K. Krieger, Y. Rudich, C. Marcolli, B. P. Luo, D. L. Bones, J. P. Reid, A. T. Lambe, M. R. Canagaratna, P. Davidovits, T. B. Onasch, D. R. Worsnop, S. S. Steimer, T. Koop and T. Peter, Atmos. Chem. Phys., 2015, 15, 13599-13613.

3 H. C. Price, J. Mattsson, Y. Zhang, A. K. Bertram, J. F. Davies, J. W. Grayson, S. T. Martin, D. O'Sullivan, J. P. Reid, A. M. J. Rickards and B. J. Murray, Chem. Sci., 2015, 6, 4876-4883.

4 B. B. Wang, A. T. Lambe, P. Massoli, T. B. Onasch, P. Davidovits, D. R. Worsnop and D. A. Knopf, J. Geophys. Res., 2012, 117, D16209.

5 T. Koop, J. Bookhold, M. Shiraiwa and U. Pöschl, Phys. Chem. Chem. Phys., 2011, 13, 1923819255.

Jonathan Williams asked: The conclusions you draw pertaining to biogenic molecules clearly hold for isoprene and monoterpenes. However, would this also be true for heavier species such as sesquiterpenes and diterpenes?

Daniel Knopf answered: The glass transition temperature $\left(T_{\mathrm{g}}\right)$ has been shown to depend on molecular weight, $\mathrm{O}: \mathrm{C}$ ratio, and water content. ${ }^{1-3}$ Assuming that sesquiterpenes and diterpenes yield heavier condensed-phase oxidation products compared to the investigated monoterpenes, $T_{\mathrm{g}}$ and corresponding full deliquescence relative humidity are likely higher in temperature and relative humidity compared to the results of the investigated biogenic secondary organic aerosol (SOA). This would imply a potentially greater role of those biogenic SOA particles in cloud glaciation processes and warrants further laboratory studies.

1 T. Berkemeier, M. Shiraiwa, U. Pöschl and T. Koop, Atmos. Chem. Phys., 2014, 14, 1251312531.

2 T. Koop, J. Bookhold, M. Shiraiwa and U. Pöschl, Phys. Chem. Chem. Phys., 2011, 13, 1923819255.

3 M. Shiraiwa, Y. Li, A. P. Tsimpidi, V. A. Karydis, T. Berkemeier, S. N. Pandis, J. Lelieveld, T. Koop and U. Pöschl, Nat. Comm., 2017, 8, 7.

Jonathan Reid commented: This is an impressive and comprehensive publication. I do have a question on the microphysical kinetic modelling. Among other quantities you require to constrain the model, you require the diffusion constant of water in the organic matrix. These are generally not known and for the systems for which they are known (particularly $\alpha$-pinene) they have not been measured at 
the temperatures you require. How dependent/sensitive are your conclusions from the kinetic modelling on the uncertainties in diffusion constants and what temperature dependent values have you assumed?

Daniel Knopf responded: In this study, we use the diffusivity estimation scheme developed in Berkemeier et al. ${ }^{1}$ With this semi-empirical scheme, the water diffusion coefficients in aqueous sucrose can be extrapolated to different, chemically similar substances. The parameters determining the diffusion coefficients are the glass transition temperature of the pure substance (in this case $\alpha$-pinene or naphthalene secondary organic aerosol, SOA) and the hygroscopicity of the material, e.g. $\kappa_{\text {org. }}$. The underlying assumptions of this methodology are: first, differences in diffusive properties are to a substantial degree due to factors such as molar mass and shape, both of which directly affect the glass transition temperature. ${ }^{2}$ Second, the way by which the glass transition is approached is not affected strongly by the SOA type, as all organic compounds relevant for SOA are fragile glass formers. ${ }^{3}$ Third, the plasticization effect of water is the same irrespective of SOA type. In Fig. S8 of Shiraiwa et al., ${ }^{4}$ it has been shown that the estimation of water diffusion coefficients in $\alpha$ pinene SOA compares well to experimentally determined values by Lienhard et al. ${ }^{5}$ Note that these measurements were published after the development of our estimation method and no fitting was performed here.

Regarding uncertainty and sensitivity of the diffusivity estimation method on the amorphous deliquescence relative humidity of SOA, this relationship is depicted in the supplementary information for Berkemeier et al., ${ }^{1}$ Fig. S4.

1 T. Berkemeier, M. Shiraiwa, U. Pöschl and T. Koop, Atmos. Chem. Phys., 2014, 14, 1251312531.

2 T. Koop, J. Bookhold, M. Shiraiwa and U. Pöschl, Phys. Chem. Chem. Phys., 2011, 13, 1923819255.

3 C. A. Angell, in National Technical Information Service, ed. K. Ngai and G. B. Wright, U. S. Department of Commerce, Springfield, VA, 1985.

4 M. Shiraiwa, Y. Li, A. P. Tsimpidi, V. A. Karydis, T. Berkemeier, S. N. Pandis, J. Lelieveld, T. Koop and U. Pöschl, Nat. Comm., 2017, 8, 7.

5 D. M. Lienhard, A. J. Huisman, U. K. Krieger, Y. Rudich, C. Marcolli, B. P. Luo, D. L. Bones, J. P. Reid, A. T. Lambe, M. R. Canagaratna, P. Davidovits, T. B. Onasch, D. R. Worsnop, S. S. Steimer, T. Koop and T. Peter, Atmos. Chem. Phys., 2015, 15, 13599-13613.

A. Ravishankara opened a general discussion of the papers by Nadine Unger, Alla Zelenyuk and Daniel Knopf: You all talked about a few interesting phenomena, each from a different perspective. The implication in your talks is that it is important to include these processes in models. How do you actually include this type of data in models? Are we giving enough thought to how specifically such information could be used and included in models?

Nadine Unger responded: Which "models" exactly? The answer depends on what you need to simulate and over which spatiotemporal scale. For instance, are you interested in simulating aerosol particulate concentrations in an urban airshed, or understanding chemical and dynamical processes that control aerosol distribution using aircraft campaign data, or the regional climate response to global aerosol loading in the future world in 2100 etc.? It is important to distinguish between CTMs and CCMs. CCMs and global Earth system models simulate their own meteorology and climatic state from scratch (and increasingly also 
other components, including dynamic vegetation and full carbon and methane cycles), which, by definition, leaves less computational resources available for the chemistry and aerosol processing, as compared to a CTM that simply reads in offline reanalysis meteorology. Therefore, CTMs can afford quite explicit and detailed process-based chemistry and aerosol representations today, e.g. as in GEOS-Chem. That said, state-of-the-science CCMs do include fairly detailed process-based chemistry and aerosol modules today too e.g. CAM5-Chem, HadGEM3-ES and many others. In response to Daniel Knopf's excellent presentation, some CCMs today are indeed at the stage of including advanced aerosol interactions with mixed-phase and ice clouds, for example we include black carbon acting as ice nuclei in some of our recent work. As a large-scale chemistryclimate modeller, the question to Alla Zelenyuk would be, do the effects of gasphase polycyclic aromatic hydrocarbons influence the regional and global radiative effects of BSOA, at scales of $\sim 100 \mathrm{~s}$ of $\mathrm{km}$ ? If the answer is yes, then we have strong motivation to move forward and implement the interactions into the global climate model. If the answer is no, but they do strongly affect the distribution of BSOA and localized weather impacts in and around megacities - then the interactions could be included in those spatiotemporal scale models.

Daniel Knopf answered: When considering implementation of our type of data into models two aspects have to be addressed. First, representation of the phase state of organic aerosol (OA) and secondary organic aerosol (SOA) particles under typical atmospheric conditions. Second, parameterization of ice nucleation rates for representative OA and SOA particles. Both aspects depend on the scale of the model, e.g. a climate model, cloud resolving, and/or atmospheric chemistry model. Shiraiwa et al. ${ }^{1}$ very recently developed a parameterization scheme implemented in the global chemistry climate model EMAC $^{2}$ that includes the organic aerosol module ORACLE ${ }^{3}$ to predict the phase state of SOA particles. Since the time steps of climate models are usually large, detailed microphysical parameterizations, as derived from our experiments, cannot be directly implemented except when employing great simplifications (e.g. by giving a fraction of the ice nucleating particles). The community applies cloud resolving models, compared against field observations, to validate ice nucleation parameterizations. Currently different ice nucleation descriptions for the various ice nucleation pathways are discussed in the literature. To facilitate implementation of immersion freezing in larger scale models, we have developed a water activity based immersion freezing model, ${ }^{4,5}$ similar to the water activity based homogeneous ice nucleation theory. ${ }^{6}$ This model is based on classical nucleation theory and requires temperature, relative humidity, and surface area of the ice nucleating particles to derive an ice nucleation rate. These parameters are available in models that treat aerosol particles and cloud formation.

1 M. Shiraiwa, Y. Li, A. P. Tsimpidi, V. A. Karydis, T. Berkemeier, S. N. Pandis, J. Lelieveld, T. Koop and U. Poschl, Nat. Comm., 2017, 8, 7.

2 P. Jockel, H. Tost, A. Pozzer, C. Bruhl, J. Buchholz, L. Ganzeveld, P. Hoor, A. Kerkweg, M. G. Lawrence, R. Sander, B. Steil, G. Stiller, M. Tanarhte, D. Taraborrelli, J. Van Aardenne and J. Lelieveld, Atmos. Chem. Phys., 2006, 6, 5067-5104.

3 A. P. Tsimpidi, V. A. Karydis, A. Pozzer, S. N. Pandis and J. Lelieveld, Geosci. Model Dev., 2014, 7, 3153-3172.

4 D. A. Knopf and P. A. Alpert, Faraday Discuss., 2013, 165, 513-534.

5 P. A. Alpert and D. A. Knopf, Atmos. Chem. Phys., 2016, 16, 2083-2107. 
6 T. Koop, B. P. Luo, A. Tsias and T. Peter, Nature, 2000, 406, 611-614.

Alla Zelenyuk replied: To understand the atmospheric implications of our experimental discoveries, we find it extremely beneficial to be working closely with the modelers. Together we have developed new modeling frameworks that we incorporate into various models (detailed multi-layer, box, 3D chemical transport, and global models) to yield improved agreement with laboratory and field data. Here is a list of relevant publications:

M. Shrivastava, S. Lou, A. Zelenyuk, R. C. Easter, R. A. Corley, B. D. Thrall, P. J. Rasch, J. D. Fast, S. L. Massey Simonich, H. Shen and S. Tao, Proc. Natl. Acad. Sci. U. S. A., 2017, 114, 1246-1251.

M. Shrivastava, C. D. Cappa, J. Fan, A. H. Goldstein, A. B. Guenther, J. L. Jimenez, C. Kuang, A. Laskin, S. T. Martin, N. L. Ng, T. Petaja, J. R. Pierce, P. J. Rasch, P. Roldin, J. H. Seinfeld, J. Shilling, J. N. Smith, J. A. Thornton, R. Volkamer, J. Wang, D. R. Worsnop, R. A. Zaveri, A. Zelenyuk and Q. Zhang, Reviews of Geophysics, 2017, DOI: 10.1002/2016RG000540.

M. Shrivastava, C. Zhao, R. C. Easter, Y. Qian, A. Zelenyuk, J. D. Fast, Y. Liu, Q. Zhang and A. Guenther, J. Adv. Model. Earth Syst., 2016, 8, 499-519.

M. Shrivastava, R. C. Easter, X. H. Liu, A. Zelenyuk, B. Singh, K. Zhang, P. L. Ma, D. Chand, S. Ghan, J. L. Jimenez, Q. Zhang, J. Fast, P. J. Rasch and P. Tiitta, J. Geophys. Res.-Atmos., 2015, 120, 4169-4195.

P. Roldin, A. C. Eriksson, E. Z. Nordin, E. Hermansson, D. Mogensen, A. Rusanen, M. Boy, E. Swietlicki, B. Svenningsson, A. Zelenyuk and J. Pagels, Atmos. Chem. Phys., 2014, 14, 79537993.

M. Shrivastava, A. Zelenyuk, D. Imre, R. Easter, J. Beranek, R. A. Zaveri and J. Fast, J. Geophys. Res.-Atmos., 2013, DOI: 10.1002/jgrd.50160.

M. Shrivastava, A. Zelenyuk, D. Imre, J. Beranek, R. Easter, R. Zaveri and J. Fast, Atmos. Chem. Phys. Discuss., 2011, 11, 20107-20139.

Gabriel Isaacman-VanWertz addressed Daniel Knopf and Alla Zelenyuk: We heard a lot about aromatics and PAHs, but these are not that representative of anthropogenic OA. Could you talk about how your results might (or might not) be specific to aromatics and what you might see if you used compounds more representative of anthropogenic OA such as branch alkanes or other saturated hydrocarbons? In particular for Alla Zelenyuk, is the observed PAH impact on particle formation and properties unique to PAHs, or would it also be observed with other gases that are present at their saturation concentration? Such an experiment would help elucidate the mechanism for the effect, and help determine if it is a chemical process, or if it is a more physical process that is sort of a "side-effect" of equilibrium partitioning.

Daniel Knopf responded: Polycyclic aromatic hydrocarbons (PAHs) stem from the incomplete combustion of fossil fuels and wood ${ }^{1}$ and as such represent an ubiquitous, chemically identifiable SOA precursor gas of the Anthropocene. Indeed, this does not necessarily mean that these chemical species dominate the organic fraction in organic aerosol (OA), but can act as a surrogate for OA which experiences a glass transition under conditions important for atmospheric ice nucleation. The glass transition temperature $\left(T_{\mathrm{g}}\right)$ has been shown to depend on molecular weight, $\mathrm{O}: \mathrm{C}$ ratio, and water content. ${ }^{2-4}$ In terms of how glassy particles impact ice nucleation, we are not aware of ice nucleation experiments using alkane or saturated hydrocarbons derived SOA. As discussed in Koop et al., ${ }^{3}$ the presence of aliphatic species with high molar mass could yield potentially similar $T_{\mathrm{g}}$ to the case of naphthalene. However, this may depend on the degree of 
oligomerization and polymerization. ${ }^{3}$ Berkemeier et al. ${ }^{2}$ have derived $T_{\mathrm{g}}$ and full deliquescence relative humidity (FDRH) for SOA particles generated from dodecane reacting with $\mathrm{OH}$ (see Fig. S4 in Berkemeier et al. ${ }^{2}$ ). Dodecane SOA showed the lowest $T_{\mathrm{g}}$ and FDRH compared to $\alpha$-pinene, isoprene, and naphthalene derived SOA, in agreement with particle bounce experiments by Saukko et $a .^{5}$ This also suggests that those SOA particles have negligible impact on mixed-phase cloud formation similar to investigated biogenic SOA particles. Ice nucleation experiments on field-collected particles from polluted environments dominated by OA and SOA indicate the potential of these OA and SOA particles to form ice, in absence of other more efficient ice nucleating particles. ${ }^{6-8}$ Overall, this question warrants further laboratory investigation to firmly assess the role of anthropogenic derived SOA particles in cloud glaciation processes.

1 K. Ravindra, R. Sokhi and R. Van Grieken, Atmos. Environ., 2008, 42, 2895-2921.

2 T. Berkemeier, M. Shiraiwa, U. Pöschl and T. Koop, Atmos. Chem. Phys., 2014, 14, 1251312531.

3 T. Koop, J. Bookhold, M. Shiraiwa and U. Pöschl, Phys. Chem. Chem. Phys., 2011, 13, 1923819255.

4 M. Shiraiwa, Y. Li, A. P. Tsimpidi, V. A. Karydis, T. Berkemeier, S. N. Pandis, J. Lelieveld, T. Koop and U. Pöschl, Nat. Comm., 2017, 8, 7.

5 E. Saukko, A. T. Lambe, P. Massoli, T. Koop, J. P. Wright, D. R. Croasdale, D. A. Pedernera, T. B. Onasch, A. Laaksonen, P. Davidovits, D. R. Worsnop and A. Virtanen, Atmos. Chem. Phys., 2012, 12, 7517-7529.

6 D. A. Knopf, P. A. Alpert, B. Wang, R. E. O’Brien, S. T. Kelly, A. Laskin, M. K. Gilles and R. C. Moffet, J. Geophys. Res., 2014, 119, 1-17.

7 B. B. Wang, A. Laskin, T. Roedel, M. K. Gilles, R. C. Moffet, A. V. Tivanski and D. A. Knopf, J. Geophys. Res., 2012, 117, D00V19.

8 D. A. Knopf, B. Wang, A. Laskin, R. C. Moffet and M. K. Gilles, Geophys. Res. Lett., 2010, 37, L11803.

Alla Zelenyuk answered: We agree that future studies should investigate the effect of other types of hydrophobic organics on the formation and properties of SOA particles. Thus far, in addition to PAHs, we characterized $\alpha$-pinene SOA particles formed in the presence of gas-phase dioctyl phthalate (DOP) and dioctyl sebacate (DOS), two plasticizers, whose concentrations in the experiments were $200 \mathrm{ppt}$ and $20 \mathrm{ppt}$. The data indicate that both DOP and DOS molecules were incorporated and trapped in the SOA particles and their presence increased the nearly non-volatile particle content, as evidenced by measured evaporation kinetics. ${ }^{1}$ Data presented in the present paper indicate chemical interactions between oxidation products of SOA precursor and PAH. We showed that the presence of PAH during SOA formation and growth results in the formation of new products, which include oligomers. Physical processes, i.e. mixing, cannot explain the observed large changes in SOA particle properties, given that the PAHs make up only a few percent of the particles formed in the presence of PAHs. In addition, as we have previously shown, equilibrium partitioning cannot explain the formation of $\alpha$-pinene SOA particles in the presence of pyrene. We have also demonstrated that the properties of particles formed in the presence of PAHs are drastically different from those of pure SOA particles with pyrene deposited on their surfaces after SOA formation. ${ }^{2}$

1 T. D. Vaden, D. Imre, J. Beranek, M. Shrivastava and A. Zelenyuk, Proc. Natl. Acad. Sci. U. S. A., 2011, 108, 2190-2195.

2 A. Zelenyuk, D. Imre, J. Beranek, E. Abramson, J. Wilson and M. Shrivastava, Environ. Sci. Technol., 2012, 46, 12459-12466. 
Alexander Archibald remarked: Just a follow up to Ravi's comment about bridging the gap between the lab and model communities. As the community is moving toward more structured approaches to code/software management, do you think that that's going to enable better linking of lab work and models?

Nadine Unger answered: I am not aware of any direct evidence to suggest that more structured approaches to code and software management enable better linking of lab work and models. CCMs and Earth system modelers welcome with open arms the improved code management strategies. I suggest that JULES and GEOS-Chem provide powerful examples of how model communities can operate most effectively with free flow of information, regular community meetings, proper accreditation, respect, and appointed "gatekeepers"/managers of the codes. Multi-faceted excellent research groups that include laboratory physical and environmental chemistry integrated with modelling across different spatiotemporal scales potentially provide a seamless way for better linking of lab studies and models. However, many IPCC-class global chemistry-climate model research institutes (government labs and universities) are not directly associated with an in-house physical chemistry laboratory, and when they are, that doesn't necessarily imply any free flow of information.

Jos Lelieveld said: I would like to suggest a partially alternative approach, coming back to a point from earlier. Models are often going too strongly toward the operational side as there is not much CPU power to spend on chemistry. Actually, I think we should use models as tools to study processes and so they should include as much detail as possible - and then scale things back for operational applications.

Nadine Unger replied: Again, which "models", impacts, and over what spatiotemporal scales exactly? I fully agree that CTMs must be used as tools to study processes including as much detail as possible. That is one of the main reasons for the existence of CTMs. CCMs and Earth system models should then utilize the information gained from CTMs about the important necessary processes for simulating radiation and climate.

Andreas Wahner said: If, as you stated, an "easy" parameterization for SOA formation dependent on biogenic precursors works better in climate runs for CMIP compared to a now available detailed chemical mechanism, what chance do you estimate for process oriented understanding of atmospheric chemistry to be used in global models ? How do we achieve a process based understanding and modelling of the atmosphere?

Nadine Unger answered: I refer back to my response to Ravi's earlier question. What is the simulation goal/objective of the global model exactly? Are you using a global CTM to understand SOA formation and processes in different regions with aircraft measurement datasets, or are you using a global CCM to calculate the radiative effects of SOA in the present and future worlds? Process-orientated understanding of atmospheric chemistry and SOA formation is already available in many global CTMs, e.g. GEOS-Chem. Several research groups have found that a fixed yield approach to simulate SOA matches available measurements and 
observations e.g. from the AMS, better than "more sophisticated" VBS-type approaches. We have limited information available at the moment to constrain the response sensitivity of SOA in models to changes in meteorology and background pollution emissions over large spatiotemporal scales, for example. In our paper presented here, the NASA climate model included a VBS-type approach to BSOA simulation. Using this approach, the model predicts that the climatic effects of anthropogenic aerosols actually enhance BSOA levels in the atmosphere; thus, increased availability of organic particles for condensation outweighs the reductions in precursor BVOC emissions. In contrast, if the model were to incorporate a fixed yield BSOA approach, the opposite sign impact would occur in response to anthropogenic aerosols, i.e. anthropogenic aerosols would suppress BSOA levels. Indeed, many state-of-the-science global climate models in the CMIP6 assessment will not represent any interactive SOA or nitrate aerosol they may prescribe offline fields from other global simulations. For global chemistry-climate and Earth system models, the key question is: what level of process-based representation of SOA formation do we need to simulate accurately the radiative effects and response to global change? 